This document is confidential and is proprietary to the American Chemical Society and its authors. Do not copy or disclose without written permission. If you have received this item in error, notify the sender and delete all copies.

\title{
Discovery of cellular roles of intramembrane proteases
}

\begin{tabular}{|r|l|}
\hline Journal: & ACS Chemical Biology \\
\hline Manuscript ID & Draft \\
\hline Manuscript Type: & Review \\
\hline Duthor: & n/a \\
\hline Complete List of Authors: & $\begin{array}{l}\text { Beard, Hester; Katholieke Universiteit Leuven, Cellular and Molecular } \\
\text { Medicine } \\
\text { Barniol-Xicota, Marta; Katholieke Universiteit Leuven, Department of } \\
\text { Cellular and Molecular Medicine } \\
\text { Yang, Jian; Katholieke Universiteit Leuven, Cellular and Molecular } \\
\text { Medicine } \\
\text { Verhelst, Steven; Katholieke Universiteit Leuven, Cellular and Molecular } \\
\text { Medicine; Leibniz-Institut fur Analytische Wissenschaften - ISAS eV }\end{array}$ \\
\hline
\end{tabular}




\section{Discovery of cellular roles of intramembrane proteases}

Hester Beard, ${ }^{\dagger, 1}$ Marta Barniol-Xicota, ${ }^{\dagger, 1}$ Jian Yang ${ }^{\dagger, 1}$ and Steven H. L. Verhelst ${ }^{\dagger \ddagger^{*}}$

${ }^{\dagger} \mathrm{KU}$ Leuven, Department of Cellular and Molecular Medicine, Laboratory of Chemical Biology, Herestr. 49, 3000 Leuven, Belgium

₹ Leibniz Institute for Analytical Sciences ISAS, e.V., Otto-Hahn-Str. 6b, 44227 Dortmund, Germany

${ }^{1}$ These authors contributed equally

*Corresponding author: steven.verhelst@isas.de, steven.verhelst@kuleuven.be 


\section{Keywords}

Activity-based probes

Gamma-secretase

Intramembrane proteolysis

Photoaffinity labeling

Rhomboid proteases

Secretome analysis

Site-2 protease 


\begin{abstract}
Intramembrane proteases (IMPs) are localized within lipid bilayers of membranes - either the cell membrane or membranes of various organelles. Cleavage of substrates often results in release from the membrane, leading to a downstream biological effect. This mechanism allows different signaling events to happen through intramembrane proteolysis. Over the years, various mechanistically distinct families of IMPs have been discovered, but the research progress has generally been slower than for soluble proteases due to the challenges associated with membrane proteins. In this review we will summarize how each mechanistic family of IMPs was discovered, which chemical tools are available for the study of IMPs and which techniques have been developed for the discovery of IMP substrates. Finally, we will discuss the various roles in cellular physiology of some of these IMPs.
\end{abstract}




\section{Introduction}

Intramembrane proteolysis was first described in 1997, when site-2 protease (S2P) was reported to cleave its substrates (SREBPs, for sterol-regulatory element-binding proteins) within a transmembrane helix $(\mathrm{TMH})$, thereby setting a dormant transcription factor free from the membrane (Figure 1A). ${ }^{2}$ The years following the discovery of S2P witnessed the discovery of several other mechanistic families of intramembrane proteases (IMPs): aspartyl IMPs, ${ }^{3456}$ serine IMPs (also known as rhomboid proteases) ${ }^{7}$ and later glutamyl IMPs ${ }^{8}$ (Figure 1C-D). The existence of different IMP families suggests that intramembrane proteolysis is not just an odd event, but that it has evolved multiple times during the course of evolution to perform critical tasks in cellular physiology.

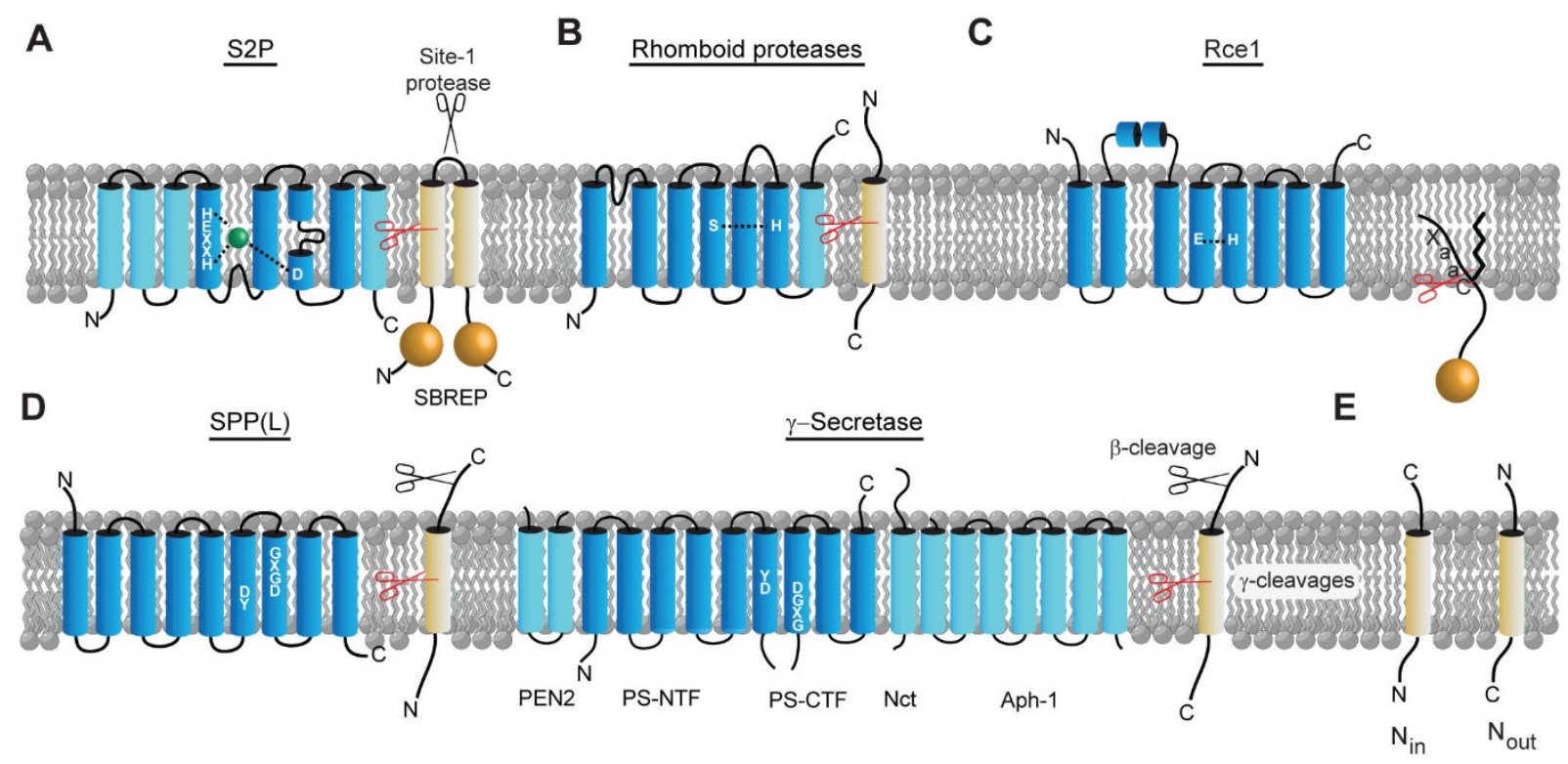

Figure 1. Overview of IMP families and their typical substrate cleavages. The space below the membrane represents the cytosol. The extracellular space or lumen is located above the membrane. Note that the TMHs that form the core protease structure are colored with a darker blue. Optional TMHs or TMHs of other proteins in the same complex (for $\gamma$-secretase) are colored in a lighter blue. Substrate TMHs are indicated in yellow. The cut-site by the IMP is depicted with orange scissors; a prerequisite cut is indicated with black scissors. (A) S2P is the prototypical metallo IMP. After proteolytic processing of SBREP in the cytosolic loop by site-1 protease, one of the TMHs becomes a substrate for S2P. After cleavage of this $\mathrm{TMH}, \mathrm{a}$ 
transciption factor is set free from the membrane. (B) Rhomboid proteases have 6 or 7 TMHs. The $7^{\text {th }} \mathrm{TMH}$ may be located C-terminally (as depicted here) or $\mathrm{N}$-terminally to the core protease structure. Their substrates do not require a prior cut. (C) Glutamyl IMPs are exemplified by Rce1. It removes the C-terminal tripeptide of the "CaaX-box" of membraneanchored, prenylated proteins. Its catalytic mechanism is not completely understood, but involves activation of a water molecule by a glutamate residue and essential involvement of a histidine in the catalytic center. (D) Aspartyl IMPs are also called GXGD IMPs after the common active site motif found in one of the TMHs. Whereas presenilin (PS) is only catalytically active within the $\gamma$-secretase complex, SPP and SPP-like proteases (SPPL) function alone. Typical substrates need a prior cut by another protease before being processed by $\operatorname{SPP}(\mathrm{L})$ or $\gamma$-secretase. The most well-known substrate is undoubtedly the amyloid precursor protein (APP). After a cut by $\beta$-secretase, $\gamma$-secretase can perform several sequential cuts in the TM of APP, leading to A $\beta$-peptides of various lengths. Some of these are the toxic peptide species that are typically found in the plaques in brains of Alzheimer's patients. (E) Topologies of IMP substrates: an IMP either cleaves a substrate with $\mathrm{N}_{\text {in }}$ topology, where the protein $\mathrm{N}$ terminus is localized in the cytoplasm (such as SPP) or with $\mathrm{N}_{\text {out }}$ topology (such as rhomboid proteases).

At first, intramembrane proteolysis seemed odd and counterintuitive because of the hydrophobic environment of the lipid bilayer, in which the peptide bond hydrolysis of the substrate takes place. Evidently, lipid membranes are not impermeable to water and crystal structures of various families of IMPs have revealed bound water molecules in close proximity to the catalytic machinery. ${ }^{8} 9$

Although three mechanistic families of IMPs have soluble counterparts that utilize similar types of chemistry in their active sites, there are clear differences in the protein structures and active site architectures. While most soluble proteases fold into a globular shape by using various structural elements including sheets, helices and random coils (Figure 2A), the core 
structures of IMPs are formed by multiple $\alpha$-helical TMHs, some of which contain the active site residues. IMPs adopt structures that may be cup-shaped (such as $\mathrm{GlpG}^{9}$ or Rce $1 ;^{8}$ Figure 2B) or horseshoe-like (such as the $\gamma$-secretase complex; ${ }^{10}$ Figure $2 \mathrm{C}$ ). Beside differences in structure, there are also differences in how soluble and intramembrane proteases recognize their substrates. Soluble proteases mostly utilize distinct binding pockets adjacent to the active site to recognize side chains of amino acid residues around the scissile peptide bond, to which is usually referred by the Schechter and Berger nomenclature of $\mathrm{P} 1, \mathrm{P} 2$, etc. for substrate residues located $\mathrm{N}$-terminally to the sciccile bond in $\mathrm{S} 1$, S2 etc. pockets on the protease (Figure 2D). ${ }^{11}$ For substrate residues and recognition pockets located C-terminally to the scissile bond, these numbers receive an apostrophe (P1', P2', S1', S2'). Soluble proteases often display a clear substrate consensus consisting of a distinct primary sequence, which may be utilized for the design of inhibitors or chemical probes. How IMPs recognize their substrates is much less clear. Rce1 may be an exception amongst IMPs: it has a well defined substrate repertoire, as it is responsible for cleavage of the "aaX" tripeptide of proteins with a prenylated cysteine in their C-terminal "CaaX box" motif. The substrate determinants of other families of IMPs remain largely elusive. One reason is the low amount of substrates that are known for individual members of IMP families. Section 4 of this review deals with the available methods for substrate discovery, but here, we will already summarize some common substrate recognition principles from two decades of IMP research. (1) IMPs cleave substrates with a particular TMH topology: either with the $\mathrm{N}$-terminus inside the cytosol ( $\mathrm{N}_{\text {in }}$; Figure 1E) or the $\mathrm{N}$-terminus oriented towards the extracellular space or the lumen of the ER or Golgi ( $\mathrm{N}_{\text {out; }}$; Figure 1E). For example, rhomboid proteases only process substrate $\mathrm{TMHs}$ with a $\mathrm{N}_{\text {out }}$ topology. (2) For metallo and most aspartyl IMPs, a prior cleavage by another protease is required, before proteolytic processing in the membrane will take place (Figure 1A and 1D). (3) To make the scissile peptide bond accessible to the catalytic machinery, the substrate helix must be unwound. Early research reports on S2P, ${ }^{12}$ signal peptide peptidase (SPP) ${ }^{13}$ and rhomboid proteases ${ }^{14}$ demonstrated that helix-breaking residues (glycine and/or proline) within the $\mathrm{TMH}$ of the substrate enable cleavage. Interestingly, introduction of a single proline into a 
$\mathrm{TMH}$ proved to be sufficient to turn a non-substrate of rhomboid into a substrate. ${ }^{15}$ Recent crystal structures of $\gamma$-secretase in complex with substrate TMHs of Notch $^{16}$ and the amyloid precursor protein (APP) ${ }^{17}$ revealed that the interaction induces a conformational change in part of the substrate TMH, which unwinds from an $\alpha$-helix into a $\beta$-strand extended conformation (Figure 2E). This strand forms a hybrid $\beta$-sheet with two other $\beta$-strands from PS-1, which are formed upon interaction with APP. ${ }^{17}$ (4) Recognition sites may be plastically formed. As mentioned above, structural rearrangements take place upon interaction of $\gamma$-secretase with its substrates. In a crystal structure of the rhomboid protease GlpG in complex with a $\beta$-lactam inhibitor, the putative S2' pocket also seems to be formed only upon binding of the inhibitor (Figure 2E). ${ }^{18}$

Compared with soluble proteases, IMPs are slow enzymes. While soluble proteases may cut multiple substrates per second (corresponding to a $k_{\text {cat }}>1 \mathrm{~s}^{-1}$ ), IMPs cut in the timeframe of minutes. ${ }^{19}$ For example, the rhomboid protease AarA from the bacterium $P$. stuartii cleaves its natural substrate TatA with a $\mathrm{k}_{\text {cat }}$ of $0.014 \mathrm{~s}^{-1}$, as described by Urban and co-workers, ${ }^{20}$ which was further corroborated by Lemieux and co-workers ${ }^{21}\left(0.018 \mathrm{~s}^{-1}\right)$. The laboratory of Steiner determined the $\mathrm{k}_{\text {cat }}$ for cleavage of APP by $\gamma$-secretase and also found very slow rates of catalysis $\left(0.0012 \mathrm{~s}^{-1}\right)$. Overall, this translates to rates of approximately 1 per minute (for TatA cleavage by rhomboid) to 4 per hour (for APP cleavage by $\gamma$-secretase).

Despite their slow catalysis, IMPs have distinct roles in cellular physiology, which is the overall theme of this review. In the first section, we will give an overview how IMPs have been discovered. Interestingly, small molecules have played an important role for the discovery of some IMP families. In the following two sections, we will summarize the available chemical tools for the study of IMPs and the methods to discover substrates of IMPs, both of which form a means towards uncovering the functional role of IMPs. In the subsequent section, we will outline the cellular roles of the different families of IMPs, with particular focus on the function in human and mammalian cells. We will end with a discussion of some future challenges for the field of intramembrane proteolysis. 
A

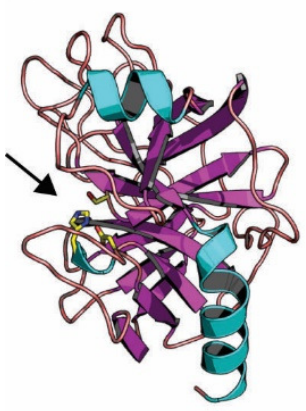

Trypsin

(B. taurus)

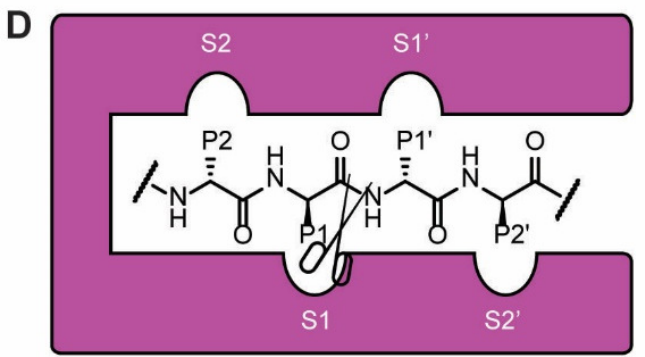

B

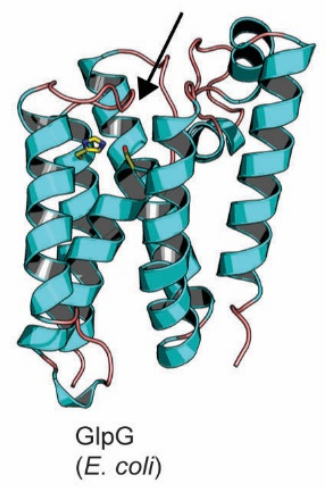

E
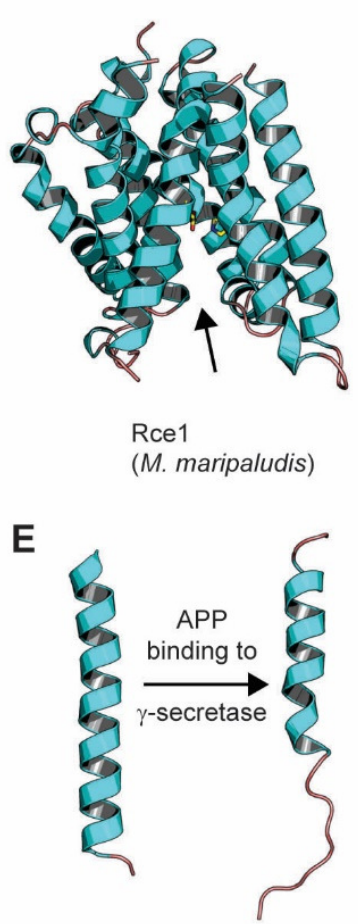

C
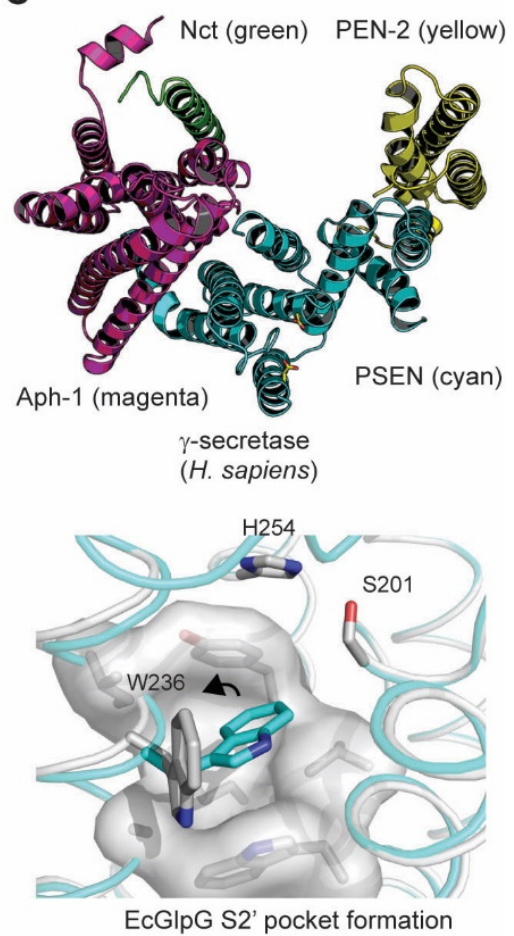

Figure 2. Comparison of soluble proteases and IMPs. (A) Crystal structure of bovine trypsin (PDB code: 1MAX) shows an overall globular structure. $\beta$-sheets are colored magenta, helices cyan and random coils pink. The arrow indicates the substrate binding cleft. Active site residues H57, D102 and S195 are depicted in stick representation. (B) Crystal structures of the IMPs E. coli GIpG (left; PDB code: 2IC8) and M. Maripaludis Rce1 (right; PDB code: 4CAD) reveal an overall cup-like structure. Helices are colored cyan, random coils pink. Note that the core structure is fully built up of helices. Arrows indicate the hydrophilic cavity near the active site (S201 and H252 of GlpG and E140 and H173 of Rce1 are depicted in stick representation). (C) CryoEM structure of human $\gamma$-secretase (PDB code: 5A63). The membrane-embedded portion of the complex is built by various helices of the four different subunits, which are each dipicted in a different color. Note that for clarity, only the membrane helix is depicted for nicastrin. (D) Summary of the Schechter and Berger nomenclature for substrate recognition by proteases. Side chains of the substrate around the scissile bond (indicated with scissors) are termed P1, P2, etc. towards the N-terminal side and P1', P2' etc. towards the C-terminal side. These side chains fit into corresponding pockets of the protease termed S1, S2, etc. and S1', 
S2' etc. (E) Examples of conformational changes during substrate recognition by IMPs. Left: part of the TMH of the substrate APP unfolds from an $\alpha$-helix to a $\beta$-strand upon binding to the $\gamma$-secretase complex (PDB codes: 2LLM and 6IYC). Right: the putative S2' pocket of the $E$. coli rhomboid GlpG only forms upon binding of an inhibitor. The apo-enzyme (PDB code: 2IC8) is colored in cyan, the inhibitor-bound enzyme (PDB code: $3 Z \mathrm{MI}$ ) in light grey. Note that the S2' pocket is formed by rotation of tryptophan W236 upon inhibitor binding. For clarity, the inhibitor structure is not depicted.

\section{Discovery of IMPs}

The possibility that proteolysis occurred within the hydrophobic environment of a membrane, was a provocative thought in the mid-' 90 s of the last century. The existence of such process was suggested in 1996 by Selkoe in an attempt to explain the formation of $A \beta$-peptides from APP in the context of Alzheimer's disease (AD). ${ }^{22}$ Although experimental proof for intramembrane proteases was still missing, Selkoe envisaged in a minireview that "[APP] may [...] undergo mechanistically enigmatic ' $y$-secretase' cleavages within the hydrophobic transmembrane domain [...]'.22 The first experimental proof of intramembrane proteolysis was provided a year later with the discovery of S2P. ${ }^{1}$ Since then, various other mechanistic families of IMPs have been identified; the below paragraphs describe the discovery process of each of these families.

\subsection{S2P (1997)}

The discovery of S2P was driven by molecular biology efforts. Goldstein and co-workers studied the cholesterol feedback regulation mechanism, when they identified the SREBP family of membrane-bound transcription factors. SREBPs are located within the membranes of the ER and the nucleus. In order to carry out their regulatory function they must undergo a two-step cleavage, first a site- 1 cleavage in the lumen of the ER, followed by a site- 2 cleavage (Figure 1A). The site-2 is located in the TMH of SREBP and its cleavage allows the N-terminal part of the protein to be released from the membrane and enter the nucleus, promoting 
transcription of genes involved in the production of cholesterol and other fatty acids. The first steps in the identification of the enzyme responsible for site-2 cleavage were taken in 1994 with the generation of a mutant Chinese Hamster Ovary $(\mathrm{CHO})$ cell line that lacked the ability to grow on cholesterol-free medium, ${ }^{23}$ as they lacked the ability to cleave SREBP at site-2. ${ }^{24}$ Transfecting these cells with various parts of human cDNA led to rescue of this phenotype and Rawson et al. finally identified the S2P gene. ${ }^{1}$ The sequencing revealed a polytopic membrane protein containing the consensus sequene HEXXH, typical for metalloproteases. Mutagenesis experiments confirmed that this motif was essential for Site-2 processing.

Ten years later, the structure of the S2P from the archaea Methanocaldococcus jannaschii was solved by Shi and co-workers. ${ }^{25}$ This study confirmed the presence of a zinc atom in the catalytic site. In addition, the general metalloprotease inhibitor 1,10-phenanthroline abolished $\mathrm{S} 2 \mathrm{P}$ proteolytic activity in a concentration dependent manner, verifying that $\mathrm{S} 2 \mathrm{P}$ is a metaldependent protease, which activates a water molecule in a similar way to soluble metalloproteases (Figure 3A).

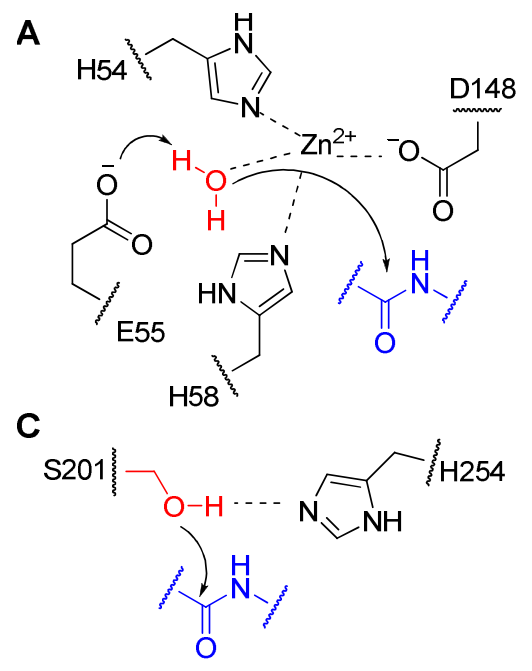

B

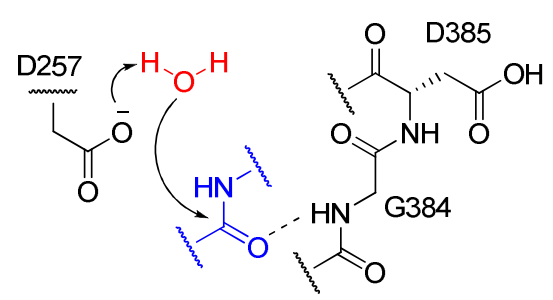

D

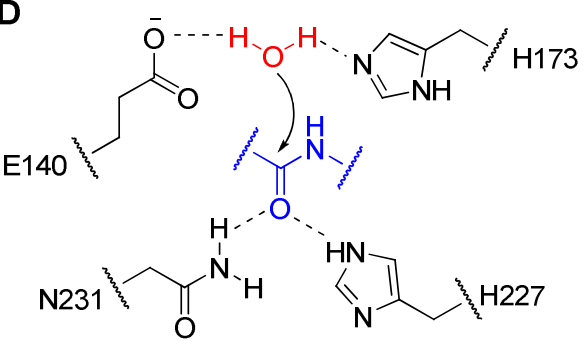

Figure 3. Catalytic mechanisms of the various IMP families. Nucleophiles are depicted in red and the scissile peptide bond of a substrate is colored blue. (A) In S2P, H54 and H58 in TMH2 and D148 in TMH4 bind a zinc ion, which also coordinates to the nucleophilic water. E55 in TM2 acts as a base that accepts the proton from the water molecule. (B) In $\gamma$-secretase, the catalytic residues comprise two aspartates (D257 in TMH6 and D385 in TMH7). Cryo-EM 
structures show that there is a hydrogen bond between the backbone of G384 and the substrate scissile bond, but the role of D385 has not become apparent. D257 likely plays the role of general base to activate the nucleophilic water molecule for attack on the scissile peptide bond. (C) In rhomboid proteases, the catalytic dyad is formed by S201 in TMH4 and H254 in TMH6 (E. coli GlpG numbering). The serine residue, activated by hydrogen bonding to the imidazole ring of the histidine, acts as a nucleophile to perform attack on the scissile peptide bond. (D) The mechanism of Rce1 involves a nucleophilic water activated by E140 in TMH4 and H173 in TMH5. The oxyanion hole is formed by residues H227 and N231 in TMH7, located opposite to the catalytic residues.

\section{$2.2 \gamma$-Secretase (2000) and SPP (2002)}

The $\gamma$-secretase complex was the first member of a second mechanistic family of IMPs that was discovered: the aspartyl IMPs, often referred to as GXGD proteases after their conserved active site sequence. The complexity of the $\gamma$-secretase complex makes its discovery process a fascinating story, which involves a powerful combination of disciplines.

In an effort to understand the pathology of $A D$, mapping of mutations that are present in familial $A D$ led to identification of two genes coding for integral membrane proteins: presenilin 1 (PS1) and presenilin 2 (PS2). ${ }^{26} 27$ Although the precise role of PS was unclear at first, it was shown that the $\gamma$-cleavage of APP and Notch depended on its presence. ${ }^{28} 29$ In the year 2000 , three different research groups reported PS as an aspartyl IMP. ${ }^{3} 45$ Interestingly, an almost identical chemical biology approach was taken by all three groups: they utilized covalent probes (see also section 3 of this review) consisting of a peptide-like transition state analog, designed to specifically interact with the active site of aspartyl proteases, combined with a covalent crosslinking moiety and a biotin as a detection tag. Affinity-labeling revealed that PS is the aspartyl IMP responsible for $\gamma$-cleavage. After this discovery, the three other essential members of the $\gamma$-secretase complex were identified: nicastrin (NCT) was reported after coimmunoprecipitation and mass spectrometry experiments, ${ }^{30}$ whereas presenilin enhancer 2 
(PEN-2) and anterior pharynx-defective $1(\mathrm{APH}-1)$ were reported as PS interaction partners during a study of the Notch pathway. ${ }^{31} 32$ The essential functional unit of $y$-secretase was defined by Haas and co-workers, who co-expressed PS, NCT, PEN-2 and APH-1 in Saccharomyces cerevisiae and observed full reconstitution of proteolytic activity. ${ }^{33} \mathrm{X}$-ray and cryo-EM structures of presinilin homologs and $\gamma$-secretase showed a large distance between the two catalytic aspartates D257 and D385, ${ }^{10}{ }^{34}$ hence these structures likely represent an inactive conformation. Recent cryo-EM structures of $\gamma$-secretase in complex with parts of the APP or Notch substrate showed more details of substrate interaction and the active site residues (Figure 3B). ${ }^{16} 17$

The other members of the aspartyl IMPs comprise the SPP family. The discovery of SPP in 2002 is another illustration of a chemical biology effort using chemical probes. Two years prior to its identification, Martoglio and co-workers already hypothesized the existence of a protease that could process signal peptides after proteolytic removal from their parent proteins. In this work, they showed that several inhibitors blocked SPP activity without affecting signal peptide removal, supporting the idea that these two proteolytic processes are carried out by different proteases. ${ }^{35}$ Although SPP was not yet identified, the authors hypothesized that it should be an intramembrane protease whose catalytic mechanism was different from S2P, which was the only known IMP at the time. In follow up work, the same research group prepared an AfBP which was based on the inhibitor used in the prior study. Photocrosslinking, biotin-mediated enrichment and mass spectrometry analysis led to the identification of SPP, a new protein whose function had not yet been elucidated. ${ }^{6}$ SPP contained typical aspartyl protease motifs, homologous to those present in PS. Active site mutagenesis experiments confirmed that SPP indeed is an aspartyl IMP.

\subsection{Rhomboid proteases (2001)}

The discovery of rhomboid proteases finds its origin in biology and genetics of epidermal growth factor (EGF) receptor signaling in the fruit fly, Drosophila melanogaster. There is only one single EGF receptor present in Drosophila and its main activating ligand is the protein 
Spitz, a homolog of mammalian TGF $\alpha$, which is bound to the membrane in a dormant form and needs a proteolytic cleavage to become a functional signaling molecule. It was known that two other gene products, Rhomboid-1 and Star, were needed for production of active Spitz, but how this happened was unknown. Freeman and co-workers elucidated the mechanism of Spitz activation in two back-to-back papers in $2001 .{ }^{76}$ In a series of experiments using Drosophila embryos and cell culture, it was shown that Star relocalizes Spitz and that cleavage of Spitz is dependent on Rhomboid-1. ${ }^{36}$ This led to the model that Star helps traffcking of Spitz from the ER to the Golgi, where Rhomboid-1 is localized. Upon cleavage, the soluble fragment of Spitz is exported from the Golgi and secreted from the cell, where it can now activate the EGF receptor. Support for the catalytic mechanism of Rhomboid-1 was provided by mutational analysis as well as the observation that Spitz cleavage is sensitive towards the general serine protease inhibitors $\mathrm{DCl}$ and TPCK. ${ }^{7}$ Although it was first thought that the catalytic mechanism involved a triad of serine, histidine and asparagine, a crystal structure of the E. coli GlpG revealed that the active site involves a catalytic dyad (Figure $3 C$ ).$^{9}$ In the years after the discovery of Rhomboid- 1 it was recognized that rhomboid proteases are present in virtually all sequenced organisms and are one of the most widespread families of integral membrane proteins. ${ }^{37}$ They can be subdivided into different classes based on their topology (see also Figure 1B): one containing only the $6 \mathrm{TMH}$ core, one with an additional C-terminal $\mathrm{TMH}$, one with an additional $\mathrm{N}$-terminal $\mathrm{TMH}$, and a class of inactive pseudoproteases termed iRhoms that lack one or more of the catalytic residues. ${ }^{38}$

\subsection{Rce1 (2013)}

Glutamyl IMPs are the latest addition to the IMP superfamily. Its only member to date, Rce1, had been identified in $S$. cerevisiae fifteen years before its catalytic mechanism was elucidated. ${ }^{39}$ Early studies found chloromethylketones, known to be cysteine protease inhibitors, to abolish Rce1 activity. The inhibition profile, together with site-directed mutagenesis experiments showing that a cysteine was required for proteolysis, initially led to classification of Rce1 as a cysteine protease. ${ }^{40}$ This model was discarded once it was shown 
that the catalytic cysteine was not conserved in bacterial homologs. Next, Rce1 was suggested to be a metalloprotease, ${ }^{41}$ although previous experiments had shown that various metal chelators did not affect proteolytic activity. ${ }^{40}$ The Rce 1 catalytic machinery identity remained a mystery, until in 2013 Manolaridis et al. solved the crystal structure of the Methanococcus maripaludis homolog MmRce1 and found that the active site is buried within the plane of the membrane. ${ }^{8}$ The currently accepted catalytic mechanism involves the carboxylate of E140 to be the general base in charge of activating the water molecule that attacks the scissile peptide bond. Histidine residue $\mathrm{H} 173$ also participates in this activation process via hydrogen bond formation with its imidazole ring. The oxyanion transition state is stabilized by H227 and N231 (Figure 3D).

\section{Chemical tools for IMP}

The study of soluble proteases has benefited tremendously from the development of chemical tools, such as activity-based probes (ABPs) and synthetic substrate reporters. ${ }^{42} 4344$ Knowledge of protease substrate specificity - in particular the primary sequence around the active site (see Figure 2D) - underlies the design of many of these tools. For IMPs, however, the substrate specificity remains poorly understood. An additional inconvenience is the difficulty to express and purify IMPs in their active forms, which has a negative impact on structural studies as well as on testing potential chemical tools. Overall, this has resulted in a much slower progress of chemical tool design for IMPs. In this paragraph, covalent chemical probes (ABPs and affinity-based probes; AfBPs), synthetic substrates and lipid nanodiscs will be discussed as currently available chemical tools to study IMPs.

\subsection{Covalent chemical probes (ABPs/AfBPs)}

Covalent chemical probes are small molecules that form a covalent bond with a specific (set of) target enzyme(s) and consequently enable visualization of the probe-enzyme complex. Covalent chemical probes can be subdivided into ABPs and AfBPs, depending on their mechanism of covalent modification. 
ABPs consist of three elements (Figure 4A), of which the warhead is perhaps the most crucial one. It exploits the hydrolysis mechanism of cysteine, serine and threonine proteases, which utilize a nucleophilic amino acid side chain in the active site for attack on the scissile bond. A reactive electrophilic warhead brought in close proximity to this side chain will form an irreversible covalent bond in a mechanism-based reaction. Note that the only IMPs utilizing such a mechanism are the rhomboid proteases. Besides a warhead, ABPs comprise a detection tag for visualization or enrichment of the tagged protease ${ }^{45}$ and a spacer, which separates the two previous elements and may also enhance the selectivity towards its targets. ${ }^{46}$ For rhomboid proteases, FP-Rhodamine (1, Figure 4A),${ }^{47} 48$ tagged isocoumarins, ${ }^{49}$ and alkynylated $\beta$-lactones ${ }^{48}$ have been reported as ABPs. These probes have been applied to the measurement of rhomboid activity and for inhibitor screening. FP-Rhodamine has been particularly useful, because it functions as a universal probe for rhomboids from various prokaryotic and eukaryotic organisms. ${ }^{50}$

Some mechanistic classes of proteases, including metallo IMPs, aspartyl IMPs and glutamyl IMPs, utilize an activated water molecule in their active site for attack on the scissile peptide bond. This mechanism does not allow the use of electrophilic 'warheads', as these would hydrolyze rather than form a covalent bond. AfBPs are alternative covalent probes that have been developed to circumvent this problem. In general, they combine a tight-binding, reversible small molecule with a photocrosslinker (for covalent binding) and a detection tag (for visualization or enrichment, Figure 4B). As mentioned before (see section 2), the development of AfBPs based on transition state inhibitors of $\gamma$-secretase, formed the basis for the discovery of PS as the catalytic subunit. ${ }^{34} 5$ It must be noted that AfBPs do not need to be derived from active site inhibitors, but have also been based on so-called $\gamma$-secretase modulators (GSMs). GSMs supposedly bind to an allosteric site and do not inhibit the $\gamma$-secretase complex, but alter the way in which it processes its substrates. Probes derived from various GSMs have been utilized in order to elucidate where these molecules bind. One example of a non-active site directed AfBP is E2012-BPyne (2, Figure 4B), which covalently crosslinks to the N-terminal 
fragment of $\mathrm{PS} 1 .^{51}$ Interestingly, labeling is not diminished in the presence of an active-site directed inhibitor or a GSM from another structural class, indicating that these compounds have different binding sites and different modes of action. ${ }^{51}$

\subsection{Synthetic substrates for IMPs}

Because IMPs require peptide recognition elements on both primed and non-primed sites, synthetic substrates for IMPs comprise fluorescently quenched peptides (or FRET peptides): a fluorophore and a quencher are incorporated at either side of the scissile bond (Figure 4C). For Rce1, the presence of an additional farnesyl group is essential for recognition. ${ }^{8}$ Whereas most synthetic substrates are based on a peptide sequence of a substrate, such as APP for $\gamma$ secretase $^{52}$ and Gurken for rhomboid proteases, ${ }^{53}$ some substrates were discovered by screening known, commercially available FRET peptides developed for soluble proteases: a recent paper by Lemieux and co-workers reported that a peptide originally developed as a substrate for the soluble metalloprotease MMP-3, could also be cleaved by various bacterial rhomboids. ${ }^{54}$

Synthetic substrates have been used for various applications, including the screening of inhibitors. For example, Pierrat et al. described a high-throughput screen for the rhomboid AarA using the Gurken-based quenched fluorescent peptide 3 (Figure 4C), resulting in the identification of $\mathrm{N}$-sulfonylated $\beta$-lactams as rhomboid inhibitors. Kinetic studies have also benefited from the development of synthetic substrates. Urban and co-workers discovered that a FITC-functionalized $\mathrm{TMH}$, when reconstituted in a liposome, does not show fluorescence until cleavage occurs and the FITC detaches from the lipid bilayer. They found that rhomboids display low $\mathrm{K}_{\text {cat }}$ values for this substrate (slow cleavage) and high $\mathrm{K}_{M}$ values (low affinity). ${ }^{20}$ Strisovsky and co-workers were able to optimize fluorescently quenched peptides consisting of a complete $\mathrm{TMH}$ by changing the amino acid sequence near the scissile bond. ${ }^{55}$ Although the cleavage efficiency $k_{c a t} / K_{M}$ could be increased more than 20 -fold, the cleavage is still on 
the timescale of minutes. Slow cleavage kinetics has also been observed for $\gamma$-secretase with recombinantly expressed polypeptides, ${ }^{56}$ suggesting that this is a general property of IMPs.

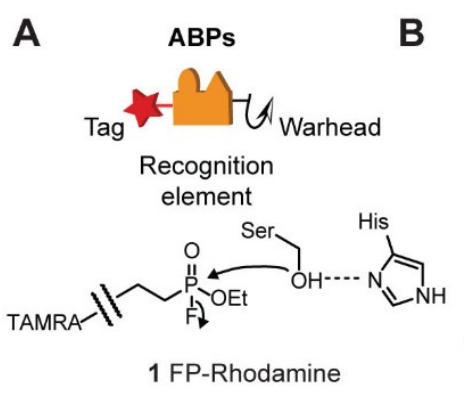

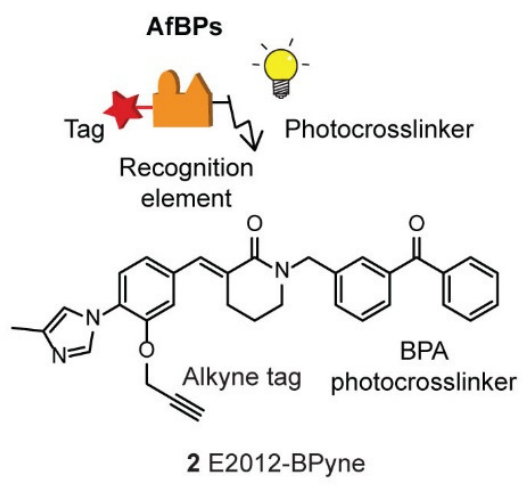

C
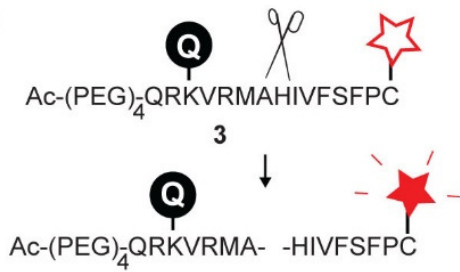

D

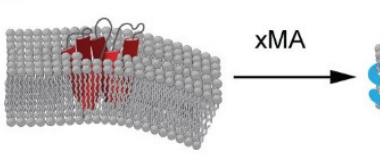

Membrane

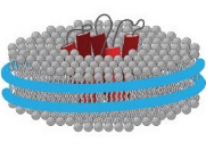

Lipid nanodisc

Figure 4. Overview of different chemical tools for studying IMPs. (A) ABPs comprise an electrophilic warhead for covalent, mechanism-based reaction with the active site, a recognition element for increased selectivity and a detection tag. Example ABP FP-Rhodamine reacts with many serine hydrolases, ${ }^{57}$ including rhomboids. Note that this $A B P$ does not have a recognition element next to the warhead, explaining its pan-reactivity. (B) AfBPs contain a photocrosslinker for photoaffinity labeling of their targets. Example probe $\mathbf{2}$ was derived from a known GSM and contains a benzophenone photocrosslinker and an alkyne tag. (C) Quenched fluorescent peptides lead to an increase in fluorescent signal over time when incubated with their target IMP. Here, a peptide based on the rhomboid substrate Gurken is depicted, bearing an N-terminal polyethyleneglycol (PEG) chain for solubility. (D) xMA polymers can solubilize membrane proteins in XMALP lipid nanodiscs.

\subsection{Lipid nanodiscs}

It is difficult to obtain IMPs in a pure, active and stable form, suggesting a low structural stability of these proteins. Indeed, even the E. coli rhomboid GlpG, which can be expressed, solubilized and purified in detergent, is thermodynamically relatively instable ${ }^{58}$ and its structure is held together by multiple weak interactions. The membrane environment may stabilize the stuctural and functional properties of IMPs. Strikingly, the most common solubilization techniques 
utilized for IMPs make use of detergent micelles, which strip away structurally and functionally important lipids.

Some recent studies have turned their attention to the generation of lipid nanodiscs in which IMPs are surrounded by lipids and kept together by a polymer. This strategy has been exploited for various other membrane proteins, such as ion channels and drug transporters. ${ }^{59}$ Especially interesting and beneficial are amphipathic polymers such as styrene maleic acid (SMA) and related co-polymers (collectively referred to as xMA), which can be directly applied to isolated membrane pellets. As a consequence, the lipids present in XMA lipid particles (xMALPs) are those in which the protein was embedded during expression in the cell (Figure 4D). The properties of these nanodiscs (e.g. their suitability for spectroscopic measurements such as circular dichroism or infrared spectroscopy) can be tuned by changing the structure of the XMA.

To date, only two IMPs have been studied in xMALPs, both rhomboid proteases: E. Coli GlpG and V. Cholerae rhomboid. Reading et al. solubilized GlpG with SMA and subsequently used hydrogen-deuterium exchange mass spectrometry to investigate the conformational dynamics of GlpG. Interestingly, certain regions in GlpG are more sensitive to changes in the membrane environment than other. ${ }^{60}$ In a separate study, the same research group used xMALPs to show that GIpG can co-translationally insert into a lipid bilayer and fold into an $\alpha$ helical structure. ${ }^{61}$ Hellwig et al. used GlpG solubilized by SMA to demonstrate the compatibility with laser-induced liquid bead ion desorption mass spectrometry, which can assess the oligomeric states of proteins. Here, they found that GlpG occurs as a monomer in the XMALPS and is surrounded by approximately 50 lipids. ${ }^{62}$ Our laboratory has recently shown that the activity of GlpG in xMALPs resembles that in the lipid membrane environment better than when isolated in micelles. More importantly, the unstable $V$. Cholerae rhomboid, which rapidly selfprocesses in a micelle environment, was stable and functionally active in XMALPs, illustrating the benefit of these lipid nanodiscs. ${ }^{63}$ We expect that XMALPs are applicable to other families of IMPs and that this type of solubilization will facilitate future structural and functional studies of IMPs. 


\section{IMP substrate discovery}

Identifying the substrate repertoire of a protease is key to understanding its cellular function. Additionally, it contributes to elucidating protease substrate specificities, which can be exploited for the development of inhibitors and chemical probes.

There are multiple ways to identify substrates of IMPs. Early stages of IMP research involved serendipitous substrate discovery by means of various biochemistry and molecular biology techniques, sometimes linked to the discovery of the IMP family itself (see also section 2 of this review). Some substrates were found by analogy with features in other substrates such as the presence of helix-breaking residues in combination with the membrane topology. For example, the unfolded protein response regulator XBP1u was identified as a substrate candidate of SPP, as it contains a type II TMH with helix-breaking residues. In addition, it also localized to the ER membrane, where SPP resides. Transient co-expression revealed that XBP1u is indeed processed by SPP. ${ }^{64}$

Although discovery of IMP substrates on an individual basis has provided clues about the cellular roles of IMPs, it is evident that a more global, unbiased IMP substrate identification is desirable. Tandem MS-based proteomics can aid in this process. Various proteomics-based substrate identification techniques have been reported for soluble proteases, and are reviewed elsewhere. 656667

Cleavage by IMPs often leads to dissociation of the substrate from the membrane. If the IMP is located at the cell surface, the substrate fragment will be released from the cell. Therefore, one approach to identifying substrates of IMPs is to analyze the cell's secretome; these methods will be discussed in the first paragraph of this section. If the IMP is located inside the cell (i.e. within an organelle membrane) cleaved substrate fragments that are released from the membrane are often degraded, hampering their detection. However, by observing the accumulation of non-cleaved substrates in knockout or inhibitor treated samples, or the depletion of substrates in wild-type versus knockout conditions, candidate substrates can be identified. These cases will be discussed in the second paragraph of this section. 
IMP substrate discovery methods usually compare two separate samples under different conditions (e.g. WT vs knockout). Therefore, relative quantification is key to reliable substrate identification. Quantification can be achieved in several ways, including label-free quantification (LFQ) and isotope labeling, such as SILAC. ${ }^{68}$ The different quantification techniques will be indicated for each individual example in below paragraphs.

\subsection{Detection of released extracellular domains}

In general, the conditioned medium of cultured cells comprises: (1) IMP substrates, (2) ectodomains of membrane proteins cleaved by membrane-bound sheddases, (3) secreted soluble proteins, (4) intracellular proteins resulting from occasional cell lysis and (5) highly abundant serum proteins from the cell culture medium. Because of (1) and (2), methods aimed at the detection of released extracellular domains can be used for the discovery of substrates of IMPs and membrane-bound sheddases.

According to the UniProt database, $87 \%$ of single pass transmembrane proteins at the cell surface are glycosylated. This property has been exploited in different ways for enrichment of cleaved proteins from serum proteins prior to MS analysis (Figure $5 \mathrm{~A}$ ). This is important because proteins named under (1) and (2) are present in low concentrations in the secretome, relative to $(5){ }^{69}$

A study towards substrates of RHBDL2, a rhomboid protease at the cell membrane, utilized lectin affinity chromatography to enrich shed cell surface proteins. SILAC-based quantification was used to compare secretomes of HEK293TET cells expressing endogenous RHBDL2 with those expressing a catalytically dead mutant. Validation of substrate candidates with a $\mathrm{H} / \mathrm{L}$ ratio of $<1$ (the active protease was expressed in the 'light' SILAC pair) yielded various new RHBDL2 substrates. ${ }^{70}$

The enrichment of shed protein fragments has also been achieved by various chemical derivatization methods. One of these, referred to as 'glyco-capture', makes use of periodatemediated oxidation of the cis-diol groups on the glycan, leading to aldehyde functionalities, which can selectively be conjugated to hydrazides to facilitate enrichment (Figure 5A). 
However, as many serum proteins are also glycosylated, it requires the use of serum-free or serum-depleted medium, which has various disadvantages including the induction of cellular stress. ${ }^{71}$ Although this method has not yet been utilized for IMPs, it has proven its value in substrate identification for membrane-bound proteases BACE1 and BACE2. ${ }^{72}$

The method of SPECS (secretome protein enrichment with click sugars) was developed to overcome the difficulty in distinguishing cell-derived glycoproteins from glycosylated serum proteins. In SPECS, cell surface glycoproteins are metabolically labeled by incubation of the cells with the azido sugar ManNAz (peracetylated $\mathrm{N}$-azidoacetyl-mannosamine). ManNaz is converted inside the cell to an azido-functionalized sialic acid, which is then incorporated into cell surface glycoproteins. ${ }^{73}$ After removal of free ManNAz by ultrafiltration, the azide-modified glycans are reacted with dibenzocyclooctyne (DBCO)-biotin for subsequent enrichment. SPECS has been used in combination with relative LFQ to identify candidate substrates of membrane-bound proteases and IMPs. Benefits of SPECS include the use of normal serum concentrations and enhanced protein sequence coverage due to the purification and enrichment of secreted proteins. SPECS has originally been validated for the membranebound protease BACE $1,{ }^{74}$ but since then also been utilized to identify substrates of SPPL3. These were identified in both human and murine cell culture models by quantitatively comparing the glycoprotein secretome between cells overexpressing SPPL3 and SPPL3deficient cells. ${ }^{75}$ The majority of identified substrates were associated with the Golgi network, involved in $\mathrm{N}$ - and O-glycosylation pathways. 


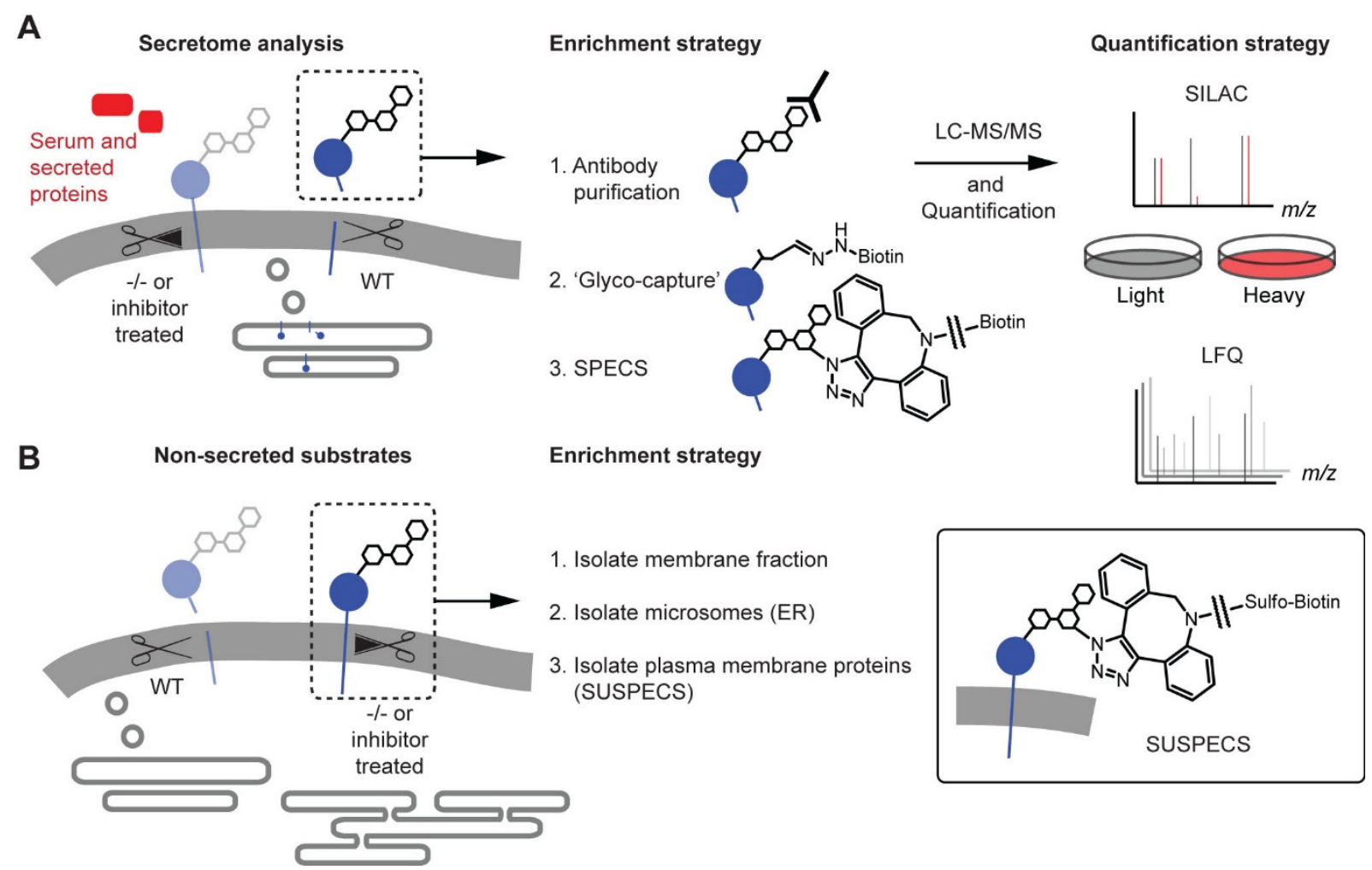

Figure 5. Strategies for identification of IMP substrates. (A) Analysis of the secretome requires enrichment of the cleaved substrates (boxed) from other secreted proteins and serum proteins. Note that the IMP substrates that end up in the secretome can originate from cleavages at the cell membrane but also in the Golgi, followed by secretion. Enrichment strategies include antibody-based purification, 'glyco-capture' involving glycan oxidation and subsequent biotinylation, or SPECS, where cells are first incubated with azidomonosaccharides followed by 'click'-reaction with a biotin reagent. Quantification can take place with isotope labels, such as SILAC, or label-free. (B) Non-secreted substrates can be identified by comparison of WT and knock-out or inhibitor treated cells. Usually, membrane proteins are enriched from the soluble protein background by isolating the membrane fraction, the microsomal fraction or by enriching cell surface proteins with 'SUSPECS', which makes use of a membrane impermeable 'sulfo-biotin' click reagent.

\subsection{Detection of non-secreted substrates}

The majority of IMPs located within the cell do not generate a secreted fragment. In these cases, other methods are required to identify IMP substrates. This can be done by 
quantitatively analyzing changes in protein abundance within the whole proteome between WT and knockout or inhibitor-treated samples. Because the soluble protein fraction would present an enormous amount of background proteins, virtually all proteomics studies of IMP substrates specifically isolate the membrane fraction.

The very first proteomics study towards IMP substrates focused on $\gamma$-secretase and made use of SILAC labeling. Substrates were identified by comparing membrane fractions of HeLa cell populations treated with the $\gamma$-secretase inhibitor DAPT (light labeled cells) and a DMSO control (heavy labeled cells). After fractionation by SDS-PAGE, in-gel digestion and LC-MS/MS analysis, accumulated $\gamma$-secretase substrate candidates were identified by means of their SILAC ratio and further validated by expression in cell culture. ${ }^{76}$ Validated substrates comprised $\mathrm{N}^{\text {out }} \mathrm{TMH}$ proteins whose ectodomain was shed prior to $\gamma$-secretase cleavage, in agreement with the general model of $\gamma$-secretase processing.

SILAC has also been combined with differential organelle proteomics to identify membrane proteins that were depleted upon expression of SPP (and therefore potential SPP substrates). As SPP is localized to the ER, the microsomal fraction was analyzed from HEK293T cells transfected with an empty vector, SPP WT or a catalytic SPP mutant. This study enabled the identification of the SNARE protein STX18 as a novel SPP substrate. ${ }^{77}$ Overall, this highlights the benefit of separating (potential) substrates from the bulk of the proteome.

Although SILAC has some substantial advantages in proteomic analyses, it is a relatively expensive technique. Label-free quantification (LFQ) has recently been employed as an alternative quantification technique in IMP substrate discovery. For example, novel substrates of SPPL2c were identified by comparing the proteomes of testis membrane preparations from wild-type and SPPL2c knockout mice. ${ }^{78}$ The tail-anchored proteins phospholamban and syntaxin 8 were found to be significantly enriched in the knockout testis sample and independently validated as substrates. In a separate study, a variety of vesicular transportassociated proteins were identified as SPPL2c substrates by comparing changes in protein abundance from ectopic expression of SPPL2C in HEK293 cells and a SPPL2c-deficient control, using LFQ methods. ${ }^{79}$ 
A variant of the SPECS method that enables identification of non-cleaved substrates on the cell surface may find future use in the identification of IMP substrates. Surface-spanning

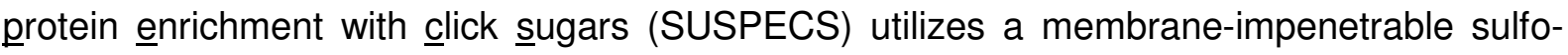
variant of DBCO-biotin, resulting in the specific labeling of cell surface proteins. Although not yet applied to IMPs, SUSPECS was used to identify 7 known BACE1 substrates and one novel BACE1 candidate substrate by comparing the surface glycoproteome of primary cortical neurons treated with a BACE1 inhibitor versus a DMSO control. $^{80}$

\subsection{Cleavage site analysis}

Knowledge of the cleavage site of IMP substrates and the sequence or structural requirements around the scissile bond may help future design of small molecule chemical probes as well as inhibitors. However, the above described techniques do not directly reveal the cleavage site, because they focus on the enrichment of a protein fragment rather than the neo $\mathrm{N}$ - or $\mathrm{C}$ terminus that is formed by substrate hydrolysis. A plethora of " $\mathrm{N}$-terminomics" and " $\mathrm{C}$ terminomics" methods has been reported for the discovery of cleavage sites of soluble proteases. Some of the most well known examples include terminal amine isotopic labeling of substrates (TAILS) ${ }^{81}$ and combined fractional diagonal chromatography (COFRADIC) ${ }^{82}$ For details on terminomics methods, we refer the reader to some recent reviews. ${ }^{6667}$

The methods described in sections 4.1 and 4.2 reveal IMP substrates by analyzing the shed extracellular protein fragment or the depleted membrane anchored protein. Because of the focus on analyzing proteins or protein fragments, the substrates are identified through multiple tryptic or semi-tryptic peptides, which increases the confidence of protein identification. In contrast, $\mathrm{N}$ - or C-terminomics methods, which specifically enrich one end of the cleavage site, only identify the substrate with a single semi-tryptic peptide. Inherently, this may be problematic for IMP substrates: as the cleavage site lies within a $\mathrm{TMH}$ or in the juxtamembrane region, the semi-tryptic peptides will be (1) much longer and (2) more hydrophobic than peptides derived from soluble proteases. Both issues may present a bottleneck for terminomics methods for IMPs. However, the use of other digestive enzymes in 
combination with trypsin should result in shorter peptides, while a potential solution to problem (2) may lie in derivitization of neo-N- or C-terminal peptides with reagents that give highly ionizable peptides.

Despite the lack of application of terminomics methods to IMPs, cleavage site analysis has been done on a case-to-case basis. In one study, purified fragments of RHBDL2 substrates were used to determine their cleavage sites. ${ }^{70}$ Following digestion of the substrate fragments with trypsin or ArgC, LC-MS/MS analysis was used to identify the most C-terminal semi-tryptic or semi-ArgC peptides. Interestingly, all substrates were found to be cleaved at a single site after a small amino acid (in the P1 position) within or close to the $\mathrm{N}$-terminal portion of the TMH. In their study towards substrates of SPPL3, Kuhn et al. searched the acquired proteomics data for semitryptic peptides spanning the TM helix and juxtamembrane domain. Various cleavage sites were identified, with large hydrophobic residues in P1 (M or $\mathrm{Y}$ ) and in P1' (L, Y or I). ${ }^{75}$

\section{Physiological functions of IMPs}

In the last two decades, it has become clear that IMPs have a wide variety of functions within the cell. In the paragraphs below, we will discuss some of these functions, with particular attention to their roles in mammalian cells.

\section{$5.1 \mathrm{~S} 2 \mathrm{P}$}

In mammalian cells, S2P is embedded in the Golgi membrane. To date, the identified substrates comprise transcription factors that are dormant in their membrane-bound form. For a detailed description of these functions, we refer to the review of Rawson. ${ }^{2}$ In short, these transcription factors become activated after two separate cleavage events: a first cleavage by site-1 protease in the lumen of the Golgi and a second cleavage within a TM by the IMP S2P.

The SREBPs were the first S2P substrates to be discovered. ${ }^{1}$ SREBPs have two TMs, connected by a short loop. The N-terminus contains the transcription factor, whereas the Cterminus features a regulatory domain, which interacts with the SREBP cleavage activating 
protein (Scap). Under normal circumstances, SREBPs are located in the ER. When there is a need for lipids within the cell, the SREBP-Scap complex travels from the ER to the Golgi. In the lumen of the Golgi, the loop of SREBP is first cleaved by site-1 protease, after which the remaining TM-anchored transcription factor becomes a substrate for S2P (see Figure 1A). Cleavage within the TM leads to release from the membrane, which allows the transcription factor to relocate to the nucleus, where it induces expression of genes required for lipid biosynthesis.

Most other mammalian substrates of S2P are membrane-bound transcription factors involved in the ER stress response. For example, ATF6, the second S2P substrate to be discovered, is involved in the unfolded protein response. ${ }^{83}$ Normally, it is bound to the ER membrane with a single TM and interacts with the ER chaperone BiP. Upon accumulation of unfolded proteins in the ER, BiP dissociates from ATF6, exposing a Golgi localization signal, resulting in transport to the Golgi, subsequent processing by site-1 protease and S2P, respectively, which leads to release of the transcription factor. ${ }^{84}$

S2Ps do not only occur in eukaryotes, but are also widespread amongst species of bacteria and archaea. $^{85}$ Generally, these prokaryotic homologs are involved in the cleavage of membrane-bound transcriptional regulators. In E. coli, for example, the inner membrane protein RseA acts as an anti-sigma factor that holds the sigma factor $\mathrm{E}$ (SigE) inactive. Upon extracytoplasmic stress, RseA is first cleaved by DegS ${ }^{86}$ (which acts as the "site-1 protease"), and subsequently by RseP (formerly known as YaeL), ${ }^{87} 88$ the S2P of E. coli. The RseA-SigE complex is now set free into the cytosol, where the RseA fragment is escorted by the SspB adaptor to the ClpXP protease complex, which degrades RseA ${ }^{89}$ This finally leads to liberation of SigE, which is now able to bind to RNA polymerase for activation of target gene transcription (Figure 6A). It must be noted that the coupling of the two first proteolytic cleavages by site-1 protease and S2P is not yet fully understood. In addition, there are also examples of bacterial substrates that do not need a first processing step and can be cleaved by S2P directly. For a more detailed overview on this matter, we refer to a review of Schneider and Glickman. ${ }^{90}$ 


\subsection{Aspartyl IMPs}

This section will be subdivided into two paragraphs: one dealing with SPP and the SPP-like proteases SPPL2a-c and SPPL3, the other one with PS1 and PS2, which require three other components for activity within the $\gamma$-secretase complex.

\subsubsection{SPP and SPPL}

The ER-resident SPP was initially reported to process signal peptides, which are $N$-terminal sequences that target nascent proteins to the ER and are cleaved off by another protease, named signal peptidase. ${ }^{6}$ However, it is not clear if cleavage by SPP is the only mechanism that removes remnants of signal peptides from the ER membrane. Moreover, SPP function is not restricted to the cleavage of signal peptides. Recently, it has been revealed that SPP also plays a role in ER-associated protein degradation (ERAD) - not of misfolded proteins, which are 'pulled' out of the membrane by an AAA-ATPase, but of intact ER-localized membrane proteins. ${ }^{91}$ For example, the tail-anchored protein heme oxygenase-1 $(\mathrm{HO}-1)$ was discovered as a substrate of SPP by comparative proteomics of membrane preparations in SPP WT and knockout cells using SILAC-based quantification. After cleavage, the cytosolic fragment is ubiquitinylated and subsequently degraded by the proteasome (Figure 6B). ${ }^{92}$ In Plasmodium falciparum, the malaria-causing parasite, inhibition of SPP also leads to disruption of ERAD, resulting in senzitation towards ER stress and inhibition of liver-stage parasites. ${ }^{93}$ Hence, selective SPP inhibtion of the parasite may be a possible antimalarial strategy.

SPPL proteases are located in different cellular components: late endosomes/lysosomes (SPPL2a), the plasma membrane (SPPL2b), ER (SPPL2c), and the Golgi apparatus (SPPL3). ${ }^{94}$ Most substrates of SPPL2a and SPPL2b require prior shedding of the ectodomain, after which SPPL2a/b processes the remaining membrane-embedded TM helix (Figure 1D). Examples include TNF $\alpha^{95}{ }^{96}$ (which is first cleaved by the membrane-bound metalloprotease ADAM17) and CD74, the invariant chain of MHC class II (which is first cleaved by cathepsin S). ${ }^{97} 9899$ Cleavage by SPPL2a/b leads to release from the membrane, which may induce 
further signalling. The intracellular domain of the invariant chain, for example, travels to the nucleus where it influences gene transcription. ${ }^{100}$

SPPL2c is endogenously expressed in murine and human testis. Substrates of SPPL2c have recently been reported by comparative proteomics with LFQ (see also section 4.2). SPPL2C promotes male germ cell development by processing phospholamban, ${ }^{78}$ a regulator of the calcium transporter SERCA2, and by cleaving SNARE proteins, ${ }^{79}$ thereby decreasing vesicle fusion and intracellular trafficking. The Golgi-localized SPPL3 plays a role in several $\mathrm{N}$ - and $\mathrm{O}$ glycosylation pathways. Specifically, it cleaves membrane-bound glycosyltransferases, such as $N$-acetylglucosaminyltransferase $V$ and $\beta$-1,4-galactosyltransferase-1, ${ }^{75} 101$ whose release from the membrane reduces their cellular activity. Accordingly, overexpression of SPPL3 led to hypoglycosylation of glycoproteins, pointing towards a role of SPPL3 in post-translational modification of proteins by regulation of glycosylation.

\subsubsection{PS as part of the $\gamma$-secretase complex}

In humans, two homologs of PS are present: PS1 and PS2. The PS subunit is only catalytically active as part of the $\gamma$-secretase complex with NCT, APH-1 and PEN-2 as additional subunits required to stabilize the complex and aid substrate binding. ${ }^{33} 102 \mathrm{As} \mathrm{APH}-1$ has two different isoforms, in principle, four different types of $\gamma$-secretase complexes may occur in the cell. In humans, PS1 predominantly localizes to the Golgi, plasma membrane and endosomes, whereas PS2 is found mainly in late endosomes and lysosomes. ${ }^{103} 104$

APP is probably the most well known substrate of $\gamma$-secretase, because of its link to AD. In the non-amyloidogenic pathway, APP undergoes ectodomain shedding by a-secretase prior to $\gamma$-secretase cleavage, releasing a small soluble p3 peptide. However, in the amyloidogenic pathway, $\beta$-secretase cleavage precedes that of $\gamma$-secretase, resulting in the production of $A \beta$ peptides of varying lengths. Mutations in PS1, PS2 and APP correlate with the production of longer, more aggregation-prone $A \beta$-peptides, ${ }^{105}$ which accumulate in the amyloid plaques of Alzheimer's patients - a hallmark of AD. Consequently, there has been interest in the 
development of drugs that could modulate this process. However, $\gamma$-secretase inhibitors have failed in clinical trials because of mechanism-based toxicities resulting from inhibition of cleavage of substrates other than APP, such as Notch. ${ }^{106}$

Notch signalling is initiated by binding of a ligand bound to a neighboring cell to the Notch receptor, which induces a series of proteolytic cleavages. Following an initial cut by the metalloprotease ADAM10, proteolysis by $\gamma$-secretase results in the release of Notch intracellular domain (NICD), which translocates to nucleus where it regulates transcription. Notch signalling plays an important role in embryonic development via regulation of cell proliferation, differentiation and apoptosis. ${ }^{107}$ This pathway is dysregulated in many tumor types and for this reason, repurposing of $\gamma$-secretase inhibitors for cancer treatment has been explored. ${ }^{108}$

\subsection{Rhomboid proteases}

Drosophila rhomboid-1 was originally found to cleave the membrane-anchored TGF $\alpha$-like growth factor Spitz and consequently activate the EGF receptor (see also section 2 of this review). ${ }^{76}$ However, in mammals, cleavage of TGF $\alpha$ and EGF is performed by membranebound metalloproteases; hence, rhomboids were likely to play another role in the cellular physiology of mammalian cells.

To date, only detailed information about the functions of RHBDL2, RHBDL4 and PARL (presenilin-associated rhomboid-like) has been described. Each is located within a different organelle: RHBDL2 is located at the plasma membrane, RHBDL4 resides in the ER, and PARL is present in the inner mitochondrial membrane.

Currently, RHBDL2 is the mammalian rhomboid for which most substrates have been reported. Thrombomodulin ${ }^{109}$ and B-type ephrins ${ }^{110}$ were identified as substrates of RHBDL2 by looking at similarities of the TMH with that of Spitz. Freeman and co-workers found that EGF is a substrate for RHBDL2 by trying out coexpression of EGF with various mammalian rhomboid proteases in COS7 cells. ${ }^{111}$ Because these substrates can also be processed by membrane-bound metalloproteases, the physiological relevance of these cleavages is 
currently unclear. Johnson et al. used a systematic approach of SILAC-based quantitative proteomics based (see also section 4 of this review) to identify a multiple substrates of RHBDL2, ${ }^{70}$ including Cadm1, CLCP1 and KIRREL, which are not cleaved by metalloproteases ADAM10 and ADAM17. The expression of RHBDL2 predominantly in epithelial tissues together with the previously reported roles of the identified substrates in cell adhesion and migration processes, points towards a functional role of RHBDL2 in epithelial homeostasis. ${ }^{70}$ The functional role of RHBDL4 has been debated. While Song et al. suggested that it cleaves TGF $\alpha$ at the plasma membrane, inducing tumor growth, ${ }^{112}$ Lemberg and co-workers showed that RHBDL4 induces trafficking of proTGF $\alpha$, eventually resulting in its secretion in microvesicles (which is more in line with the localization of RHBDL4 in the ER membrane). ${ }^{113}$ The group of Munter reported that RHBDL4 is capable of cleaving APP, preventing its processing by $\beta$ - and $\gamma$-secretase, and decreasing $A \beta$-peptide levels. ${ }^{114}$ However, the physiological relevance of RHBDL4 in AD is still unclear. A more general role for RHBDL4, which is upregulated upon ER stress, was shown in the ERAD pathway. RHBDL4 recognizes single spanning and polytopic membrane protein substrates by interaction with unstable TMHs as well as by interaction of a polyubiquitin chain with a ubiquitin interaction motif on RHBDL4. ${ }^{115}$ Overall, this leads to cleavage of the substrate and eventually proteasomal degradation (Figure $6 C)$.

In 2010 and 2011, several independent research groups reported that the mitochondrial rhomboid protease PARL cleaves PINK1, a mitochondrial kinase whose release into the cytosol results in its degradation by the proteasome. ${ }^{116} 117118119$ However, upon mitochondrial damage, a low membrane potential prevents insertion of the $\mathrm{TMH}$ into the inner mitochondrial membrane and subsequent cleavage by PARL. As a result, full-length PINK1 accumulates on the outer mitochondrial membrane. Recruitment of the E3 ubiquitin ligase Parkin to PINK1 then causes ubiquitinylation of proteins at the surface of the mitochondrion, finally leading to mitophagy. ${ }^{120}$ Interestingly, PARL has been linked to both Parkinson's disease and type 2 diabetes, ${ }^{121}$ but the connection with the cellular role of PARL in mitophagy is still unclear. 
For the roles of rhomboid proteases in species other than mammals, we refer to various specialized reviews. ${ }^{122} 123124$

\subsection{Glutamyl IMPs}

The only member of the glutamyl IMP family consists of the Ras and a-factor converting enzyme 1 (Rce1), which is located in the ER-membrane. ${ }^{125}$ Rce 1 is involved in the processing of prenylated proteins.

Prenylation is a post-translational modification at the C-terminal end of target proteins, which affects membrane localization and function. It involves the alkylation (by farnesyl or geranylgeranyl) of a specific cysteine residue in the so-called CaaX box, where ' $C$ ' stands for cysteine, ' $a$ ' for an aliphatic amino acid and ' $X$ ' for several amino acids, which determine whether the cysteine is farnesylated or geranylgeranylated (e.g. methionine or leucine). The C-terminal aaX tripeptide is subsequently cleaved and the free carboxylic acid of the cysteine is methylated. The former process is carried out by Rce1.

The proteolytic removal of the C-terminal aaX-tripeptide by Rce1 is essential for the proper localization and function of prenylated proteins. As protein prenylation affects many diverse biological processes, the impact of Rce1 function is profound. The most well known prenylated proteins are perhaps the Ras subfamily of GTPases, whose activation leads to signaling with cell growth and division as downstream effects. Unsurprisingly, constitutively active Ras is found in many cancer types, and Rce1 inhibition may be a viable strategy to reduce tumor growth. Other prenylated proteins are the Rho subfamily of GTPases, which are the major regulators of synaptic plasticity. Interestingly, recent findings suggest the levels of prenylated proteins are elevated in $A D$ brains, making Rce1 modulation a possible route for neurodegeneration therapies. ${ }^{126}$

Rce1 also plays a role in infectious agents. For example, the Rce1 ortholog of protozoan $T$. Brucei, the causative agent of African sleeping sickness, is essential for the viability of the parasite. ${ }^{127}$ Because of its low similarity with human Rce1, this may be a candidate for development of future anti-protozoan drugs. 
To date, most information about the biological role of Rce 1 has been obtained through knockout models. Because of the lack of potent and selective inhibitors, it remains unclear whether pharmacological interference can corroborate these roles and confirm that Rce1 can be utilized as a drug target. For a more thorough compilation of research around Rce1, we refer to the detailed review of Hampton et al. ${ }^{128}$

\section{Conclusions and future challenges}

Intramembrane proteolysis, originally thought to be an odd event, is a process common to organisms from all kingdoms of nature. In eukaryotes, IMPs occur in membranes of various organelles, underlining the importance of their biological roles. The physiological functions of IMPs are very broad and include amongst others the processing of prenylated proteins, the removal of signal peptides, transcription factor signaling and ERAD.

Since 1997 four different mechanistic families of IMPs have been reported: metallo, aspartyl, serine and glutamyl IMPs. The first three share their mechanism of action with soluble proteases. Although the architecture of the active sites and the arrangement of catalytic residues is different from those in soluble proteases, the chemistry that is utilized for peptide bond hydrolysis is comparable. Soluble proteases, however, comprise two additional mechanistic families: threonine and cysteine proteases. Do threonine and cysteine IMPs exist and if so, how could they be discovered? In soluble threonine proteases, such as the proteasomal $\beta$-subunits and taspase-1, a catalytic $\mathrm{N}$-terminal threonine residue functions as nucleophile and base. ${ }^{129} 130$ However, the occurrence of an N-terminal threonine in a TMH seems impossible, as the charged end of an IMP will be localized outside of the membrane. The MEROPS peptidase database ${ }^{131}$ lists several poorly characterized self-cleaving enzymes that utilize a threonine residue for their action. In addition, the protease HopB1 from Pseudomonas syringae depends on threonine, histidine and aspartate residues to cleave substrates. ${ }^{132}$ Hence, despite the higher steric hindrance of the nucleophilic hydroxyl group of threonine compared with serine, the activation of this hydroxyl group by a neighboring basic residue may be possible, even within the context of a lipid bilayer. Cysteines have a higher 
nucleophilicity than serines. Deprotonation by a basic amino acid side chain greatly enhances their reactivity and this might also occur inside a membrane. We think that chemical tools known as 'reactivity probes', as reported for cysteine and tyrosine residues, ${ }^{133} 134135$ may be instrumental in the discovery of these putative classes of IMPs.

As mentioned above, the roles of IMPs in cellular physiology are very diverse. However, the function of IMPs in many organisms is still unknown. To elucidate the biochemical pathways in which IMPs are involved, substrate discovery plays a crucial role: it is only after processing of a substrate that IMPs can cause a downstream biological effect. Clearly, substrate discovery methods for IMPs are still in their infancy and we expect that continuous developments will further support the elucidation of functional roles for IMPs. Terminomics methods, as performed for many different soluble proteases, ${ }^{6566} 67$ may also be applied to IMPs. However, adjustments of the experimental protocols are probably necessary in order to accomodate the identification of semi-tryptic peptides derived from TMs. If successfully applied, such studies would not only facilitate the identification of novel substrates, but also elucidate the primary sequence around the scissile bond. Although it is unclear how important the substrate's primary peptide sequence is for recognition by various IMP families, the usefullness of knowledge of the scissile bond is illustrated by various inhibitors of Rce $1^{136}$ and rhomboid proteases, ${ }^{137} 138139$ that have been synthesized based on the primary amino acid sequence around the cleavage site.

Can IMPs be used as future drug targets? IMPs play various roles not only in normal cellular physiology but also in pathological conditions. ${ }^{140}$ In the above sections, we have mentioned some functions of IMP in human disease, such as in the life cycle of the malaria parasite Plasmodium falciparum. Perhaps the most well studied IMP in drug development is $\gamma$ secretase, because of its role in the human pathophysiology of AD. Unfortunately, $\gamma$-secretase inhibitors have failed in clinical trials, but may be repurposed as anti-cancer drugs. ${ }^{141}$ As an alternative, $\gamma$-secretase modulators (GSMs) have been developed. These aim to alter the cleavage of APP to produce shorter, less toxic A $\beta$-peptides while allowing processing of other substrates. ${ }^{142}$ Unfortunately, to date, no GSMs have progressed beyond phase III clinical trials 
and several pharmaceutical companies have halted their $\gamma$-secretase drug development programs. However, we expect that the more detailed structural insight of $\gamma$-secretase ${ }^{16}{ }^{17}$ and the increased functional understanding of how the longer, toxic $A \beta$ peptides are formed ${ }^{143}$ will give a new impetus to $\gamma$-secretase drug development. We think that future research on IMPs in the area of structural biology, chemical biology and cell biology will likely result in the identification of IMP family members as new drug targets, and that a combined effort in academia and industry will lead to new drug candidates, which may eventually be used to treat human disease.

\section{Acknowledgements}

We thank financial support by H2020 (Marie Curie Individual Fellowship to MBX), Stichting Alzheimer Foundation, the China Scholarship Council, Research Foundation Flanders FWO, the Ministerium für Kultur und Wissenschaft des Landes Nordrhein-Westfalen, the Regierende Bürgermeister von Berlin-inkl. Wissenschaft und Forschung, and the Bundesministerium für Bildung und Forschung.

\section{References}

1. Rawson, R. B., Zelenski, N. G., Nijhawan, D., Ye, J., Sakai, J., Hasan, M. T., Chang, T. Y., Brown, M. S., and Goldstein, J. L. (1997) Complementation cloning of S2P, a gene encoding a putative metalloprotease required for intramembrane cleavage of SREBPs, Mol Cell 1, 47-57.

2. Rawson, R. B. (2013) The site-2 protease, Biochim Biophys Acta 1828, 2801-2807.

3. Li, Y. M., Xu, M., Lai, M. T., Huang, Q., Castro, J. L., DiMuzio-Mower, J., Harrison, T., Lellis, C., Nadin, A., Neduvelil, J. G., Register, R. B., Sardana, M. K., Shearman, M. S., Smith, A. L., Shi, X. P., Yin, K. C., Shafer, J. A., and Gardell, S. J. (2000) Photoactivated gamma-secretase inhibitors directed to the active site covalently label presenilin 1, Nature 405, 689-694.

4. Seiffert, D., Bradley, J. D., Rominger, C. M., Rominger, D. H., Yang, F., Meredith, J. E., Jr., Wang, Q., Roach, A. H., Thompson, L. A., Spitz, S. M., Higaki, J. N., Prakash, S. R., Combs, A. P., Copeland, R. A., Arneric, S. P., Hartig, P. R., Robertson, D. W., Cordell, B., Stern, A. M., Olson, R. E., and Zaczek, R. (2000) Presenilin-1 and -2 are molecular targets for gamma-secretase inhibitors, $J$ Biol Chem 275, 34086-34091.

5. Esler, W. P., Kimberly, W. T., Ostaszewski, B. L., Diehl, T. S., Moore, C. L., Tsai, J. Y., Rahmati, T., Xia, W., Selkoe, D. J., and Wolfe, M. S. (2000) Transition-state analogue inhibitors of gammasecretase bind directly to presenilin-1, Nat Cell Biol 2, 428-434. 
6. Weihofen, A., Binns, K., Lemberg, M. K., Ashman, K., and Martoglio, B. (2002) Identification of signal peptide peptidase, a presenilin-type aspartic protease, Science 296, 2215-2218.

7. Urban, S., Lee, J. R., and Freeman, M. (2001) Drosophila Rhomboid-1 defines a family of putative intramembrane serine proteases, Cell 107, 173-182.

8. Manolaridis, I., Kulkarni, K., Dodd, R. B., Ogasawara, S., Zhang, Z., Bineva, G., O'Reilly, N., Hanrahan, S. J., Thompson, A. J., Cronin, N., Iwata, S., and Barford, D. (2013) Mechanism of farnesylated CAAX protein processing by the intramembrane protease Rce1, Nature 504, 301-305.

9. Wang, Y., Zhang, Y., and Ha, Y. (2006) Crystal structure of a rhomboid family intramembrane protease, Nature 444, 179-180.

10. Bai, X. C., Yan, C., Yang, G., Lu, P., Ma, D., Sun, L., Zhou, R., Scheres, S. H., and Shi, Y. (2015) An atomic structure of human gamma-secretase, Nature 525, 212-217.

11. Schechter, I., and Berger, A. (1967) On the size of the active site in proteases. I. Papain, Biochem Biophys Res Commun 27, 157-162.

12. Ye, J., Dave, U. P., Grishin, N. V., Goldstein, J. L., and Brown, M. S. (2000) Asparagine-proline sequence within membrane-spanning segment of SREBP triggers intramembrane cleavage by site-2 protease, Proc Natl Acad Sci U S A 97, 5123-5128.

13. Lemberg, M. K., and Martoglio, B. (2002) Requirements for signal peptide peptidase-catalyzed intramembrane proteolysis, Mol Cell 10, 735-744.

14. Urban, S., and Freeman, M. (2003) Substrate specificity of rhomboid intramembrane proteases is governed by helix-breaking residues in the substrate transmembrane domain, Mol. Cell 11, 1425-1434.

15. Moin, S. M., and Urban, S. (2012) Membrane immersion allows rhomboid proteases to achieve specificity by reading transmembrane segment dynamics, eLife 1, e00173.

16. Yang, G., Zhou, R., Zhou, Q., Guo, X., Yan, C., Ke, M., Lei, J., and Shi, Y. (2019) Structural basis of Notch recognition by human gamma-secretase, Nature 565, 192-197.

17. Zhou, R., Yang, G., Guo, X., Zhou, Q., Lei, J., and Shi, Y. (2019) Recognition of the amyloid precursor protein by human gamma-secretase, Science 363.

18. Vinothkumar, K. R., Pierrat, O. A., Large, J. M., and Freeman, M. (2013) Structure of rhomboid protease in complex with beta-lactam inhibitors defines the S2' cavity, Structure 21, 10511058.

19. Langosch, D., Scharnagl, C., Steiner, H., and Lemberg, M. K. (2015) Understanding intramembrane proteolysis: from protein dynamics to reaction kinetics, Trends Biochem Sci.

20. Dickey, S. W., Baker, R. P., Cho, S., and Urban, S. (2013) Proteolysis inside the membrane is a rategoverned reaction not driven by substrate affinity, Cell 155, 1270-1281.

21. Arutyunova, E., Panwar, P., Skiba, P. M., Gale, N., Mak, M. W., and Lemieux, M. J. (2014) Allosteric regulation of rhomboid intramembrane proteolysis, Embo J 33, 1869-1881.

22. Selkoe, D. J. (1996) Amyloid beta-protein and the genetics of Alzheimer's disease, J Biol Chem 271, 18295-18298.

23. Hasan, M. T., Chang, C. C., and Chang, T. Y. (1994) Somatic cell genetic and biochemical characterization of cell lines resulting from human genomic DNA transfections of Chinese hamster ovary cell mutants defective in sterol-dependent activation of sterol synthesis and LDL receptor expression, Somat Cell Mol Genet 20, 183-194.

24. Sakai, J., Duncan, E. A., Rawson, R. B., Hua, X., Brown, M. S., and Goldstein, J. L. (1996) Sterolregulated release of SREBP-2 from cell membranes requires two sequential cleavages, one within a transmembrane segment, Cell 85, 1037-1046.

25. Feng, L., Yan, H., Wu, Z., Yan, N., Wang, Z., Jeffrey, P. D., and Shi, Y. (2007) Structure of a site-2 protease family intramembrane metalloprotease, Science 318, 1608-1612.

26. Sherrington, R., Rogaev, E. I., Liang, Y., Rogaeva, E. A., Levesque, G., Ikeda, M., Chi, H., Lin, C., Li, G., Holman, K., Tsuda, T., Mar, L., Foncin, J. F., Bruni, A. C., Montesi, M. P., Sorbi, S., Rainero, I., Pinessi, L., Nee, L., Chumakov, I., Pollen, D., Brookes, A., Sanseau, P., Polinsky, R. J., Wasco, W., Da Silva, H. A., Haines, J. L., Perkicak-Vance, M. A., Tanzi, R. E., Roses, A. D., Fraser, P. E., 
Rommens, J. M., and St George-Hyslop, P. H. (1995) Cloning of a gene bearing missense mutations in early-onset familial Alzheimer's disease, Nature 375, 754-760.

27. Levy-Lahad, E., Wasco, W., Poorkaj, P., Romano, D. M., Oshima, J., Pettingell, W. H., Yu, C. E., Jondro, P. D., Schmidt, S. D., Wang, K., and et al. (1995) Candidate gene for the chromosome 1 familial Alzheimer's disease locus, Science 269, 973-977.

28. De Strooper, B., Saftig, P., Craessaerts, K., Vanderstichele, H., Guhde, G., Annaert, W., Von Figura, K., and Van Leuven, F. (1998) Deficiency of presenilin-1 inhibits the normal cleavage of amyloid precursor protein, Nature 391, 387-390.

29. De Strooper, B., Annaert, W., Cupers, P., Saftig, P., Craessaerts, K., Mumm, J. S., Schroeter, E. H., Schrijvers, V., Wolfe, M. S., Ray, W. J., Goate, A., and Kopan, R. (1999) A presenilin-1dependent gamma-secretase-like protease mediates release of Notch intracellular domain, Nature 398, 518-522.

30. Yu, G., Nishimura, M., Arawaka, S., Levitan, D., Zhang, L., Tandon, A., Song, Y. Q., Rogaeva, E., Chen, F., Kawarai, T., Supala, A., Levesque, L., Yu, H., Yang, D. S., Holmes, E., Milman, P., Liang, Y., Zhang, D. M., Xu, D. H., Sato, C., Rogaev, E., Smith, M., Janus, C., Zhang, Y., Aebersold, R., Farrer, L. S., Sorbi, S., Bruni, A., Fraser, P., and St George-Hyslop, P. (2000) Nicastrin modulates presenilin-mediated notch/glp-1 signal transduction and betaAPP processing, Nature 407 , 4854.

31. Steiner, H., Winkler, E., Edbauer, D., Prokop, S., Basset, G., Yamasaki, A., Kostka, M., and Haass, C. (2002) PEN-2 is an integral component of the gamma-secretase complex required for coordinated expression of presenilin and nicastrin, J Biol Chem 277, 39062-39065.

32. Lee, S. F., Shah, S., Li, H., Yu, C., Han, W., and Yu, G. (2002) Mammalian APH-1 interacts with presenilin and nicastrin and is required for intramembrane proteolysis of amyloid-beta precursor protein and Notch, J Biol Chem 277, 45013-45019.

33. Edbauer, D., Winkler, E., Regula, J. T., Pesold, B., Steiner, H., and Haass, C. (2003) Reconstitution of gamma-secretase activity, Nat Cell Biol 5, 486-488.

34. Li, X., Dang, S., Yan, C., Gong, X., Wang, J., and Shi, Y. (2013) Structure of a presenilin family intramembrane aspartate protease, Nature 493, 56-61.

35. Weihofen, A., Lemberg, M. K., Ploegh, H. L., Bogyo, M., and Martoglio, B. (2000) Release of signal peptide fragments into the cytosol requires cleavage in the transmembrane region by a protease activity that is specifically blocked by a novel cysteine protease inhibitor, Journal of Biological Chemistry 275, 30951-30956.

36. Lee, J. R., Urban, S., Garvey, C. F., and Freeman, M. (2001) Regulated intracellular ligand transport and proteolysis control EGF signal activation in Drosophila, Cell 107, 161-171.

37. Koonin, E. V., Makarova, K. S., Rogozin, I. B., Davidovic, L., Letellier, M. C., and Pellegrini, L. (2003) The rhomboids: a nearly ubiquitous family of intramembrane serine proteases that probably evolved by multiple ancient horizontal gene transfers, Genome Biology 4, R19.

38. Lemberg, M. K., and Freeman, M. (2007) Functional and evolutionary implications of enhanced genomic analysis of rhomboid intramembrane proteases, Genome Res 17, 1634-1646.

39. Boyartchuk, V. L., Ashby, M. N., and Rine, J. (1997) Modulation of Ras and a-factor function by carboxyl-terminal proteolysis, Science 275, 1796-1800.

40. Dolence, J. M., Steward, L. E., Dolence, E. K., Wong, D. H., and Poulter, C. D. (2000) Studies with recombinant Saccharomyces cerevisiae CaaX prenyl protease Rce1p, Biochemistry 39, 40964104.

41. Pei, J., and Grishin, N. V. (2001) Type II CAAX prenyl endopeptidases belong to a novel superfamily of putative membrane-bound metalloproteases, Trends Biochem Sci 26, 275-277.

42. Serim, S., Haedke, U., and Verhelst, S. H. L. (2012) Activity-based probes for the study of proteases: recent advances and developments, ChemMedChem 7, 1146-1159.

43. Sanman, L. E., and Bogyo, M. (2014) Activity-based profiling of proteases, Annu Rev Biochem 83, 249-273. 
44. Chakrabarty, S., Kahler, J. P., van de Plassche, M. A. T., Vanhoutte, R., and Verhelst, S. H. L. (2019) Recent Advances in Activity-Based Protein Profiling of Proteases, Curr Top Microbiol Immunol 420, 253-281.

45. Sadaghiani, A. M., Verhelst, S. H. L., and Bogyo, M. (2007) Tagging and detection strategies for activity-based proteomics, Curr Opin Chem Biol 11, 20-28.

46. Haedke, U., Kuttler, E. V., Vosyka, O., Yang, Y., and Verhelst, S. H. L. (2013) Tuning probe selectivity for chemical proteomics applications, Curr Opin Chem Biol 17, 102-109.

47. Sherratt, A. R., Blais, D. R., Ghasriani, H., Pezacki, J. P., and Goto, N. K. (2012) Activity-Based Protein Profiling of the Escherichia coli GlpG Rhomboid Protein Delineates the Catalytic Core, Biochemistry 51, 7794-7803.

48. Wolf, E. V., Zeissler, A., Vosyka, O., Zeiler, E., Sieber, S., and Verhelst, S. H. (2013) A new class of rhomboid protease inhibitors discovered by activity-based fluorescence polarization, PLoS One 8, e72307.

49. Vosyka, O., Vinothkumar, K. R., Wolf, E. V., Brouwer, A. J., Liskamp, R. M., and Verhelst, S. H. L. (2013) Activity-based probes for rhomboid proteases discovered in a mass spectrometrybased assay, Proc Natl Acad Sci U S A 110, 2472-2477.

50. Wolf, E. V., Zeissler, A., and Verhelst, S. H. (2015) Inhibitor fingerprinting of rhomboid proteases by activity-based protein profiling reveals inhibitor selectivity and rhomboid autoprocessing, ACS Chem Biol 10, 2325-2333.

51. Pozdnyakov, N., Murrey, H. E., Crump, C. J., Pettersson, M., Ballard, T. E., Am Ende, C. W., Ahn, K., $\mathrm{Li}$, Y. M., Bales, K. R., and Johnson, D. S. (2013) gamma-Secretase modulator (GSM) photoaffinity probes reveal distinct allosteric binding sites on presenilin, J Biol Chem 288, 9710 9720.

52. Farmery, M. R., Tjernberg, L. O., Pursglove, S. E., Bergman, A., Winblad, B., and Naslund, J. (2003) Partial purification and characterization of gamma-secretase from post-mortem human brain, J Biol Chem 278, 24277-24284.

53. Pierrat, O. A., Strisovsky, K., Christova, Y., Large, J., Ansell, K., Bouloc, N., Smiljanic, E., and Freeman, M. (2011) Monocyclic beta-lactams are selective, mechanism-based inhibitors of rhomboid intramembrane proteases, ACS Chem. Biol. 6, 325-335.

54. Arutyunova, E., Jiang, Z., Yang, J., Kulepa, A. N., Young, H. S., Verhelst, S., O'Donoghue, A. J., and Lemieux, M. J. (2018) An internally quenched peptide as a new model substrate for rhomboid intramembrane proteases, Biol Chem 399, 1389-1397.

55. Ticha, A., Stanchev, S., Skerle, J., Began, J., Ingr, M., Svehlova, K., Polovinkin, L., Ruzicka, M., Bednarova, L., Hadravova, R., Polachova, E., Rampirova, P., Brezinova, J., Kasicka, V., Majer, P., and Strisovsky, K. (2017) Sensitive Versatile Fluorogenic Transmembrane Peptide Substrates for Rhomboid Intramembrane Proteases, J Biol Chem 292, 2703-2713.

56. Kamp, F., Winkler, E., Trambauer, J., Ebke, A., Fluhrer, R., and Steiner, H. (2015) Intramembrane proteolysis of beta-amyloid precursor protein by gamma-secretase is an unusually slow process, Biophys J 108, 1229-1237.

57. Bachovchin, D. A., Ji, T., Li, W., Simon, G. M., Blankman, J. L., Adibekian, A., Hoover, H., Niessen, S., and Cravatt, B. F. (2010) Superfamily-wide portrait of serine hydrolase inhibition achieved by library-versus-library screening, Proc. Natl. Acad. Sci. USA 107, 20941-20946.

58. Baker, R. P., and Urban, S. (2012) Architectural and thermodynamic principles underlying intramembrane protease function, Nat. Chem. Biol. 8, 759-768.

59. Lee, S. C., Khalid, S., Pollock, N. L., Knowles, T. J., Edler, K., Rothnie, A. J., O, R. T. T., and Dafforn, T. R. (2016) Encapsulated membrane proteins: A simplified system for molecular simulation, Biochim Biophys Acta 1858, 2549-2557.

60. Reading, E., Hall, Z., Martens, C., Haghighi, T., Findlay, H., Ahdash, Z., Politis, A., and Booth, P. J. (2017) Interrogating Membrane Protein Conformational Dynamics within Native Lipid Compositions, Angew Chem Int Ed Engl 56, 15654-15657. 
61. Harris, N. J., Reading, E., Ataka, K., Grzegorzewski, L., Charalambous, K., Liu, X., Schlesinger, R., Heberle, J., and Booth, P. J. (2017) Structure formation during translocon-unassisted cotranslational membrane protein folding, Sci Rep 7, 8021.

62. Hellwig, N., Peetz, O., Ahdash, Z., Tascon, I., Booth, P. J., Mikusevic, V., Diskowski, M., Politis, A., Hellmich, Y., Hanelt, I., Reading, E., and Morgner, N. (2018) Native mass spectrometry goes more native: investigation of membrane protein complexes directly from SMALPs, Chem Commun (Camb) 54, 13702-13705.

63. Barniol-Xicota, M., and Verhelst, S. H. L. (2018) Stable and Functional Rhomboid Proteases in Lipid Nanodiscs by Using Diisobutylene/Maleic Acid Copolymers, J Am Chem Soc 140, 14557-14561.

64. Chen, C. Y., Malchus, N. S., Hehn, B., Stelzer, W., Avci, D., Langosch, D., and Lemberg, M. K. (2014) Signal peptide peptidase functions in ERAD to cleave the unfolded protein response regulator XBP1u, EMBO J 33, 2492-2506.

65. Schilling, O., and Overall, C. M. (2007) Proteomic discovery of protease substrates, Curr Opin Chem Biol 11, 36-45.

66. Vizovisek, M., Vidmar, R., Fonovic, M., and Turk, B. (2016) Current trends and challenges in proteomic identification of protease substrates, Biochimie 122, 77-87.

67. Marino, G., Eckhard, U., and Overall, C. M. (2015) Protein Termini and Their Modifications Revealed by Positional Proteomics, ACS Chem Biol 10, 1754-1764.

68. Ong, S. E., Blagoev, B., Kratchmarova, I., Kristensen, D. B., Steen, H., Pandey, A., and Mann, M. (2002) Stable isotope labeling by amino acids in cell culture, SILAC, as a simple and accurate approach to expression proteomics, Mol Cell Proteomics 1, 376-386.

69. Makridakis, M., and Vlahou, A. (2010) Secretome proteomics for discovery of cancer biomarkers, $J$ Proteomics 73, 2291-2305.

70. Johnson, N., Brezinova, J., Stephens, E., Burbridge, E., Freeman, M., Adrain, C., and Strisovsky, K. (2017) Quantitative proteomics screen identifies a substrate repertoire of rhomboid protease RHBDL2 in human cells and implicates it in epithelial homeostasis, Sci Rep 7, 7283.

71. Huse, J. T., Liu, K., Pijak, D. S., Carlin, D., Lee, V. M., and Doms, R. W. (2002) Beta-secretase processing in the trans-Golgi network preferentially generates truncated amyloid species that accumulate in Alzheimer's disease brain, J Biol Chem 277, 16278-16284.

72. Stutzer, I., Selevsek, N., Esterhazy, D., Schmidt, A., Aebersold, R., and Stoffel, M. (2013) Systematic proteomic analysis identifies beta-site amyloid precursor protein cleaving enzyme 2 and 1 (BACE2 and BACE1) substrates in pancreatic beta-cells, J Biol Chem 288, 10536-10547.

73. Saxon, E., and Bertozzi, C. R. (2000) Cell surface engineering by a modified Staudinger reaction, Science 287, 2007-2010.

74. Kuhn, P. H., Koroniak, K., Hogl, S., Colombo, A., Zeitschel, U., Willem, M., Volbracht, C., Schepers, U., Imhof, A., Hoffmeister, A., Haass, C., Rossner, S., Brase, S., and Lichtenthaler, S. F. (2012) Secretome protein enrichment identifies physiological BACE1 protease substrates in neurons, EMBO J. 31, 3157-3168.

75. Kuhn, P. H., Voss, M., Haug-Kroper, M., Schroder, B., Schepers, U., Brase, S., Haass, C., Lichtenthaler, S. F., and Fluhrer, R. (2015) Secretome analysis identifies novel signal Peptide peptidase-like 3 (Sppl3) substrates and reveals a role of Sppl3 in multiple Golgi glycosylation pathways, Mol Cell Proteomics 14, 1584-1598.

76. Hemming, M. L., Elias, J. E., Gygi, S. P., and Selkoe, D. J. (2008) Proteomic profiling of gammasecretase substrates and mapping of substrate requirements, PLoS Biol 6, e257.

77. Avci, D., and Lemberg, M. K. (2019) Membrane Protein Dislocation by the Rhomboid Pseudoprotease Dfm1: No Pore Needed? Mol Cell 69, 161-162.

78. Niemeyer, J., Mentrup, T., Heidasch, R., Muller, S. A., Biswas, U., Meyer, R., Papadopoulou, A. A., Dederer, V., Haug-Kroper, M., Adamski, V., Lullmann-Rauch, R., Bergmann, M., Mayerhofer, A., Saftig, P., Wennemuth, G., Jessberger, R., Fluhrer, R., Lichtenthaler, S. F., Lemberg, M. K., and Schroder, B. (2019) The intramembrane protease SPPL2c promotes male germ cell development by cleaving phospholamban, EMBO Rep 20. 
79. Papadopoulou, A. A., Muller, S. A., Mentrup, T., Shmueli, M. D., Niemeyer, J., Haug-Kroper, M., von Blume, J., Mayerhofer, A., Feederle, R., Schroder, B., Lichtenthaler, S. F., and Fluhrer, R. (2019) Signal Peptide Peptidase-Like 2c (SPPL2c) impairs vesicular transport and cleavage of SNARE proteins, EMBO Rep 20.

80. Herber, J., Njavro, J., Feederle, R., Schepers, U., Muller, U. C., Brase, S., Muller, S. A., and Lichtenthaler, S. F. (2018) Click Chemistry-mediated Biotinylation Reveals a Function for the Protease BACE1 in Modulating the Neuronal Surface Glycoproteome, Mol Cell Proteomics 17, 1487-1501.

81. Kleifeld, O., Doucet, A., auf dem Keller, U., Prudova, A., Schilling, O., Kainthan, R. K., Starr, A. E., Foster, L. J., Kizhakkedathu, J. N., and Overall, C. M. (2010) Isotopic labeling of terminal amines in complex samples identifies protein $\mathrm{N}$-termini and protease cleavage products, Nat Biotechnol 28, 281-288.

82. Gevaert, K., Goethals, M., Martens, L., Van Damme, J., Staes, A., Thomas, G. R., and Vandekerckhove, J. (2003) Exploring proteomes and analyzing protein processing by mass spectrometric identification of sorted N-terminal peptides, Nat Biotechnol 21, 566-569.

83. Ye, J., Rawson, R. B., Komuro, R., Chen, X., Dave, U. P., Prywes, R., Brown, M. S., and Goldstein, J. L. (2000) ER stress induces cleavage of membrane-bound ATF6 by the same proteases that process SREBPs, Mol Cell 6, 1355-1364.

84. Shen, J., Chen, X., Hendershot, L., and Prywes, R. (2002) ER stress regulation of ATF6 localization by dissociation of BiP/GRP78 binding and unmasking of Golgi localization signals, Dev Cell 3, 99111.

85. Kinch, L. N., Ginalski, K., and Grishin, N. V. (2006) Site-2 protease regulated intramembrane proteolysis: sequence homologs suggest an ancient signaling cascade, Protein Sci 15, 84-93.

86. Ades, S. E., Connolly, L. E., Alba, B. M., and Gross, C. A. (1999) The Escherichia coli sigma(E)dependent extracytoplasmic stress response is controlled by the regulated proteolysis of an anti-sigma factor, Genes Dev 13, 2449-2461.

87. Kanehara, K., Ito, K., and Akiyama, Y. (2002) YaeL (EcfE) activates the sigma(E) pathway of stress response through a site-2 cleavage of anti-sigma(E), RseA, Genes Dev 16, 2147-2155.

88. Alba, B. M., Leeds, J. A., Onufryk, C., Lu, C. Z., and Gross, C. A. (2002) DegS and YaeL participate sequentially in the cleavage of RseA to activate the sigma(E)-dependent extracytoplasmic stress response, Genes Dev 16, 2156-2168.

89. Flynn, J. M., Levchenko, I., Sauer, R. T., and Baker, T. A. (2004) Modulating substrate choice: the SspB adaptor delivers a regulator of the extracytoplasmic-stress response to the AAA+ protease ClpXP for degradation, Genes Dev 18, 2292-2301.

90. Schneider, J. S., and Glickman, M. S. (2013) Function of site-2 proteases in bacteria and bacterial pathogens, Biochim Biophys Acta 1828, 2808-2814.

91. Avci, D., and Lemberg, M. K. (2015) Clipping or Extracting: Two Ways to Membrane Protein Degradation, Trends Cell Biol 25, 611-622.

92. Boname, J. M., Bloor, S., Wandel, M. P., Nathan, J. A., Antrobus, R., Dingwell, K. S., Thurston, T. L., Smith, D. L., Smith, J. C., Randow, F., and Lehner, P. J. (2014) Cleavage by signal peptide peptidase is required for the degradation of selected tail-anchored proteins, J Cell Biol 205, 847-862.

93. Harbut, M. B., Patel, B. A., Yeung, B. K., McNamara, C. W., Bright, A. T., Ballard, J., Supek, F., Golde, T. E., Winzeler, E. A., Diagana, T. T., and Greenbaum, D. C. (2012) Targeting the ERAD pathway via inhibition of signal peptide peptidase for antiparasitic therapeutic design, Proc Natl Acad Sci U S A 109, 21486-21491.

94. Mentrup, T., Fluhrer, R., and Schroder, B. (2017) Latest emerging functions of SPP/SPPL intramembrane proteases, Eur J Cell Biol 96, 372-382.

95. Fluhrer, R., Grammer, G., Israel, L., Condron, M. M., Haffner, C., Friedmann, E., Bohland, C., Imhof, A., Martoglio, B., Teplow, D. B., and Haass, C. (2006) A gamma-secretase-like intramembrane cleavage of TNFalpha by the GxGD aspartyl protease SPPL2b, Nat Cell Biol 8, 894-896. 
96. Friedmann, E., Hauben, E., Maylandt, K., Schleeger, S., Vreugde, S., Lichtenthaler, S. F., Kuhn, P. H., Stauffer, D., Rovelli, G., and Martoglio, B. (2006) SPPL2a and SPPL2b promote intramembrane proteolysis of TNFalpha in activated dendritic cells to trigger IL-12 production, Nat Cell Biol 8, 843-848.

97. Schneppenheim, J., Dressel, R., Huttl, S., Lullmann-Rauch, R., Engelke, M., Dittmann, K., Wienands, J., Eskelinen, E. L., Hermans-Borgmeyer, I., Fluhrer, R., Saftig, P., and Schroder, B. (2013) The intramembrane protease SPPL2a promotes B cell development and controls endosomal traffic by cleavage of the invariant chain, $J$ Exp Med 210, 41-58.

98. Beisner, D. R., Langerak, P., Parker, A. E., Dahlberg, C., Otero, F. J., Sutton, S. E., Poirot, L., Barnes, W., Young, M. A., Niessen, S., Wiltshire, T., Bodendorf, U., Martoglio, B., Cravatt, B., and Cooke, M. P. (2013) The intramembrane protease Sppl2a is required for B cell and DC development and survival via cleavage of the invariant chain, $J$ Exp Med 210, 23-30.

99. Bergmann, H., Yabas, M., Short, A., Miosge, L., Barthel, N., Teh, C. E., Roots, C. M., Bull, K. R., Jeelall, Y., Horikawa, K., Whittle, B., Balakishnan, B., Sjollema, G., Bertram, E. M., Mackay, F., Rimmer, A. J., Cornall, R. J., Field, M. A., Andrews, T. D., Goodnow, C. C., and Enders, A. (2013) B cell survival, surface $B C R$ and BAFFR expression, CD74 metabolism, and CD8- dendritic cells require the intramembrane endopeptidase SPPL2A, J Exp Med 210, 31-40.

100. Becker-Herman, S., Arie, G., Medvedovsky, H., Kerem, A., and Shachar, I. (2005) CD74 is a member of the regulated intramembrane proteolysis-processed protein family, Mol Biol Cell 16, 50615069.

101. Voss, M., Kunzel, U., Higel, F., Kuhn, P. H., Colombo, A., Fukumori, A., Haug-Kroper, M., Klier, B., Grammer, G., Seidl, A., Schroder, B., Obst, R., Steiner, H., Lichtenthaler, S. F., Haass, C., and Fluhrer, R. (2014) Shedding of glycan-modifying enzymes by signal peptide peptidase-like 3 (SPPL3) regulates cellular N-glycosylation, Embo J 33, 2890-2905.

102. Kimberly, W. T., LaVoie, M. J., Ostaszewski, B. L., Ye, W., Wolfe, M. S., and Selkoe, D. J. (2003) Gamma-secretase is a membrane protein complex comprised of presenilin, nicastrin, Aph-1, and Pen-2, Proc Natl Acad Sci U S A 100, 6382-6387.

103. Meckler, X., and Checler, F. (2016) Presenilin 1 and Presenilin 2 Target gamma-Secretase Complexes to Distinct Cellular Compartments, J Biol Chem 291, 12821-12837.

104. Sannerud, R., Esselens, C., Ejsmont, P., Mattera, R., Rochin, L., Tharkeshwar, A. K., De Baets, G., De Wever, V., Habets, R., Baert, V., Vermeire, W., Michiels, C., Groot, A. J., Wouters, R., Dillen, K., Vints, K., Baatsen, P., Munck, S., Derua, R., Waelkens, E., Basi, G. S., Mercken, M., Vooijs, M., Bollen, M., Schymkowitz, J., Rousseau, F., Bonifacino, J. S., Van Niel, G., De Strooper, B., and Annaert, W. (2016) Restricted Location of PSEN2/gamma-Secretase Determines Substrate Specificity and Generates an Intracellular Abeta Pool, Cell 166, 193-208.

105. Chavez-Gutierrez, L., Bammens, L., Benilova, I., Vandersteen, A., Benurwar, M., Borgers, M., Lismont, S., Zhou, L., Van Cleynenbreugel, S., Esselmann, H., Wiltfang, J., Serneels, L., Karran, E., Gijsen, H., Schymkowitz, J., Rousseau, F., Broersen, K., and De Strooper, B. (2012) The mechanism of gamma-Secretase dysfunction in familial Alzheimer disease, Embo J 31, 22612274.

106. De Strooper, B. (2014) Lessons from a failed gamma-secretase Alzheimer trial, Cell 159, 721-726.

107. Carrieri, F. A., and Dale, J. K. (2017) Turn It Down a Notch, Front Cell Dev Biol 4, 151.

108. Yuan, X., Wu, H., Xu, H., Xiong, H., Chu, Q., Yu, S., Wu, G. S., and Wu, K. (2015) Notch signaling: an emerging therapeutic target for cancer treatment, Cancer Lett 369, 20-27.

109. Lohi, O., Urban, S., and Freeman, M. (2004) Diverse substrate recognition mechanisms for rhomboids: Thrombomodulin is cleaved by mammalian rhomboids, Current Biology 14, 236241.

110. Pascall, J. C., and Brown, K. D. (2004) Intramembrane cleavage of ephrinB3 by the human rhomboid family protease, RHBDL2, Biochemical and Biophysical Research Communications 317, 244-252.

111. Adrain, C., Strisovsky, K., Zettl, M., Hu, L., Lemberg, M. K., and Freeman, M. (2011) Mammalian EGF receptor activation by the rhomboid protease RHBDL2, EMBO Rep. 12, 421-427. 
112. Song, W., Liu, W., Zhao, H., Li, S., Guan, X., Ying, J., Zhang, Y., Miao, F., Zhang, M., Ren, X., Li, X., Wu, F., Zhao, Y., Tian, Y., Wu, W., Fu, J., Liang, J., Wu, W., Liu, C., Yu, J., Zong, S., Miao, S., Zhang, X., and Wang, L. (2015) Rhomboid domain containing 1 promotes colorectal cancer growth through activation of the EGFR signalling pathway, Nat Commun 6, 8022.

113. Wunderle, L., Knopf, J. D., Kuhnle, N., Morle, A., Hehn, B., Adrain, C., Strisovsky, K., Freeman, M., and Lemberg, M. K. (2016) Rhomboid intramembrane protease RHBDL4 triggers ER-export and non-canonical secretion of membrane-anchored TGFalpha, Sci Rep 6, 27342.

114. Paschkowsky, S., Hamze, M., Oestereich, F., and Munter, L. M. (2016) Alternative Processing of the Amyloid Precursor Protein Family by Rhomboid Protease RHBDL4, J Biol Chem 291, 2190321912.

115. Fleig, L., Bergbold, N., Sahasrabudhe, P., Geiger, B., Kaltak, L., and Lemberg, M. K. (2012) Ubiquitindependent intramembrane rhomboid protease promotes ERAD of membrane proteins, Mol. Cell 47, 558-569.

116. Jin, S. M., Lazarou, M., Wang, C., Kane, L. A., Narendra, D. P., and Youle, R. J. (2010) Mitochondrial membrane potential regulates PINK1 import and proteolytic destabilization by PARL, J Cell Biol 191, 933-942.

117. Deas, E., Plun-Favreau, H., Gandhi, S., Desmond, H., Kjaer, S., Loh, S. H., Renton, A. E., Harvey, R. J., Whitworth, A. J., Martins, L. M., Abramov, A. Y., and Wood, N. W. (2011) PINK1 cleavage at position $\mathrm{A} 103$ by the mitochondrial protease PARL, Hum Mol Genet 20, 867-879.

118. Shi, G., Lee, J. R., Grimes, D. A., Racacho, L., Ye, D., Yang, H., Ross, O. A., Farrer, M., McQuibban, G. A., and Bulman, D. E. (2011) Functional alteration of PARL contributes to mitochondrial dysregulation in Parkinson's disease, Hum Mol Genet 20, 1966-1974.

119. Meissner, C., Lorenz, H., Weihofen, A., Selkoe, D. J., and Lemberg, M. K. (2011) The mitochondrial intramembrane protease PARL cleaves human Pink1 to regulate Pink1 trafficking, J Neurochem 117, 856-867.

120. Meissner, C., Lorenz, H., Hehn, B., and Lemberg, M. K. (2015) Intramembrane protease PARL defines a negative regulator of PINK1- and PARK2/Parkin-dependent mitophagy, Autophagy 11, 1484-1498.

121. Chan, E. Y., and McQuibban, G. A. (2013) The mitochondrial rhomboid protease: its rise from obscurity to the pinnacle of disease-relevant genes, Biochim Biophys Acta 1828, 2916-2925.

122. Rather, P. (2013) Role of rhomboid proteases in bacteria, Biochim Biophys Acta 1828, 2849-2854.

123. Santos, J. M., Graindorge, A., and Soldati-Favre, D. (2012) New insights into parasite rhomboid proteases, Mol Biochem Parasitol 182, 27-36.

124. Knopf, R. R., and Adam, Z. (2012) Rhomboid proteases in plants - still in square one? Physiol Plant 145, 41-51.

125. Schmidt, W. K., Tam, A., Fujimura-Kamada, K., and Michaelis, S. (1998) Endoplasmic reticulum membrane localization of Rce1p and Ste24p, yeast proteases involved in carboxyl-terminal CAAX protein processing and amino-terminal a-factor cleavage, Proc Natl Acad Sci U S A 95, 11175-11180.

126. Hottman, D. A., and Li, L. (2014) Protein prenylation and synaptic plasticity: implications for Alzheimer's disease, Mol Neurobiol 50, 177-185.

127. Gillespie, J. R., Yokoyama, K., Lu, K., Eastman, R. T., Bollinger, J. G., Van Voorhis, W. C., Gelb, M. H., and Buckner, F. S. (2007) C-terminal proteolysis of prenylated proteins in trypanosomatids and RNA interference of enzymes required for the post-translational processing pathway of farnesylated proteins, Mol Biochem Parasitol 153, 115-124.

128. Hampton, S. E., Dore, T. M., and Schmidt, W. K. (2018) Rce1: mechanism and inhibition, Crit Rev Biochem Mol Biol 53, 157-174.

129. Lowe, J., Stock, D., Jap, B., Zwickl, P., Baumeister, W., and Huber, R. (1995) Crystal structure of the $20 \mathrm{~S}$ proteasome from the archaeon T. acidophilum at 3.4 A resolution, Science 268, 533-539.

130. Hsieh, J. J., Cheng, E. H., and Korsmeyer, S. J. (2003) Taspase1: a threonine aspartase required for cleavage of MLL and proper HOX gene expression, Cell 115, 293-303. 
131. Rawlings, N. D., Waller, M., Barrett, A. J., and Bateman, A. (2014) MEROPS: the database of proteolytic enzymes, their substrates and inhibitors, Nucleic Acids Res 42, D503-509.

132. Li, L., Kim, P., Yu, L., Cai, G., Chen, S., Alfano, J. R., and Zhou, J. M. (2016) Activation-Dependent Destruction of a Co-receptor by a Pseudomonas syringae Effector Dampens Plant Immunity, Cell Host Microbe 20, 504-514.

133. Weerapana, E., Wang, C., Simon, G. M., Richter, F., Khare, S., Dillon, M. B., Bachovchin, D. A., Mowen, K., Baker, D., and Cravatt, B. F. (2010) Quantitative reactivity profiling predicts functional cysteines in proteomes, Nature 468, 790-795.

134. Abegg, D., Frei, R., Cerato, L., Prasad Hari, D., Wang, C., Waser, J., and Adibekian, A. (2015) Proteome-Wide Profiling of Targets of Cysteine reactive Small Molecules by Using Ethynyl Benziodoxolone Reagents, Angew Chem Int Ed Engl 54, 10852-10857.

135. Gu, C., Shannon, D. A., Colby, T., Wang, Z., Shabab, M., Kumari, S., Villamor, J. G., McLaughlin, C. J., Weerapana, E., Kaiser, M., Cravatt, B. F., and van der Hoorn, R. A. (2013) Chemical proteomics with sulfonyl fluoride probes reveals selective labeling of functional tyrosines in glutathione transferases, Chem Biol 20, 541-548.

136. Ma, Y. T., Gilbert, B. A., and Rando, R. R. (1993) Inhibitors of the isoprenylated protein endoprotease, Biochemistry 32, 2386-2393.

137. Zoll, S., Stanchev, S., Began, J., Skerle, J., Lepsik, M., Peclinovska, L., Majer, P., and Strisovsky, K. (2014) Substrate binding and specificity of rhomboid intramembrane protease revealed by substrate-peptide complex structures, Embo J 33, 2408-2421.

138. Cho, S., Dickey, S. W., and Urban, S. (2016) Crystal Structures and Inhibition Kinetics Reveal a TwoStage Catalytic Mechanism with Drug Design Implications for Rhomboid Proteolysis, Mol Cell 61, 329-340.

139. Ticha, A., Stanchev, S., Vinothkumar, K. R., Mikles, D. C., Pachl, P., Began, J., Skerle, J., Svehlova, K., Nguyen, M. T. N., Verhelst, S. H. L., Johnson, D. C., Bachovchin, D. A., Lepsik, M., Majer, P., and Strisovsky, K. (2017) General and Modular Strategy for Designing Potent, Selective, and Pharmacologically Compliant Inhibitors of Rhomboid Proteases, Cell Chem Biol 24, 1523-1536 e1524.

140. Verhelst, S. H. L. (2017) Intramembrane proteases as drug targets, Febs J 284, 1489-1502.

141. De Strooper, B., and Chavez Gutierrez, L. (2015) Learning by failing: ideas and concepts to tackle gamma-secretases in Alzheimer's disease and beyond, Annu Rev Pharmacol Toxicol 55, 419437.

142. Bursavich, M. G., Harrison, B. A., and Blain, J. F. (2016) Gamma Secretase Modulators: New Alzheimer's Drugs on the Horizon? J Med Chem 59, 7389-7409.

143. Szaruga, M., Munteanu, B., Lismont, S., Veugelen, S., Horre, K., Mercken, M., Saido, T. C., Ryan, N. S., De Vos, T., Savvides, S. N., Gallardo, R., Schymkowitz, J., Rousseau, F., Fox, N. C., Hopf, C., De Strooper, B., and Chavez-Gutierrez, L. (2017) Alzheimer's-Causing Mutations Shift Abeta Length by Destabilizing gamma-Secretase-Abetan Interactions, Cell 170, 443-456 e414. 